\title{
An electrophysiological comparison of visual categorization and recognition memory
}

\author{
TIM CURRAN \\ University of Colorado, Boulder, Colorado \\ and \\ JAMES W. TANAKA and DANIEL M. WEISKOPF \\ Oberlin College, Oberlin, Ohio
}

\begin{abstract}
Object categorization emphasizes the similarities that bind exemplars into categories, whereas recognition memory emphasizes the specific identification of previously encountered exemplars. Mathematical modeling has highlighted similaritiesin the computational requirements of these tasks, but neuropsychological research has suggested that categorization and recognition may depend on separate brain systems. Following training with families of novel visual shapes (blobs), event-related brain potentials (ERPs) were recorded during both categorizationand recognition tasks. ERPs related to early visual processing (N1, 156-200 msec) were sensitive to category membership. Middle latency ERPs (FN400 effects, 300-500 msec) were sensitive to both category membership and old/new differences. Later ERPs (parietal effects, 400-800 msec) were primarily affected by old/new differences. Thus, there was a temporal transition so that earlier processes were more sensitive to categorical discrimination and later processes were more sensitive to recognition-related discrimination. Aspects of these results are consistent with both mathematical modeling and neuropsychological perspectives.
\end{abstract}

There is a subtle distinction between the cognitive processes involved in object categorization and those involved in recognition memory for specific objects. Whereas object categorization emphasizes the process of finding similarities that bind object exemplars into categories (e.g., Spot, Fido, and Rover are dogs), recognition memory emphasizes the process of judging whether or not a particular exemplar has been previously encountered within a given context (e.g., "This dog is Spot who lives next door"). Previous research has highlighted both differences and similarities in the cognitive mechanisms thought to underlie categorization and recognition.

Neuropsychological research has emphasized differences between recognition and categorization and has fostered the view that the two abilities may depend on different brain systems. When required to classify novel dot patterns according to whether they belonged in the same category as a set of training patterns (following the method of Posner \& Keele, 1968), amnesic patients categorized as accurately as control subjects despite signifi-

This research was supported by a grant from the McDonnell-Pew Foundation Prog ram in Cognitive Neuroscience, a 21 st Century Collaborative Activity Award from the James S. McDonnell Foundation (supporting the "Perceptual Expertise Network"), National Science Foundation Grant 9729030, and National Institute of Mental Health Grant MH64812. Thanks to D. Collins, C. Piatt, M. Pollack, K. Tepe, and K. Waimey for research assistance and Electrical Geodesics for technical support. Address correspondence to T. Curran, Department of Psychology, University of Colorado, 345 UCB, Boulder, CO 80309-0345 (e-mail: tcurran@psych.colorado.edu). cant recognition memory impairments for the training patterns (Knowlton \& Squire, 1993; Squire \& Knowlton, 1995). Similar amnesic dissociations between explicit memory for exemplars and categorization have been observed with artificial grammar learning (Knowlton, Ramus, \& Squire, 1992; Knowlton \& Squire, 1996), probabilistic classification learning (Knowlton, Gluck, \& Squire, 1994; Knowlton, Mangels, \& Squire, 1996), and learning categories of novel object-like stimuli (Reed, Squire, Patalano, Smith, \& Jonides, 1999). Knowlton, Squire, and colleagues have generally interpreted these dissociations as indicating that categorization and recognition depend on separate memory systems. Recognition memory depends on a declarative memory system including the hippocampus, the medial temporal cortex, and diencephalic brain regions typically implicated in amnesia. Categorization is thought to depend on implicit memory systems that are somewhat task dependent. Most relevant to present visual categorization research, learning of visual dot patterns is related to activity within visual cortical areas, as measured with functional magnetic resonance imaging (f MRI; Reber, Stark, \& Squire, 1998a, 1998b).

In contrast to neuropsychological methods, mathematical modeling approaches have emphasized the similarities between categorization and recognition. In particular, several exemplar-based models can explain a variety of categorization and recognition phenomena (e.g., Estes, 1994; Hintzman, 1986, 1988; Medin \& Schaffer, 1978; Nosofsky, $1988,1991)$. In general, a single memory system is posited to store exemplars of individual experiences. Memory retrieval involves computing the similarity between a test item 
and the exemplars held in memory. The same exemplarbased system underlies both recognition and classification, but different decision rules are applied to each task (Nosofsky, 1988, 1991). Categorization depends on comparing a test item with stored exemplars from various categories and classifying the item as belonging to the category with which it is most similar. For example, a novel animal would be categorized as a dog if its similarity to stored dog exemplars is higher than its similarity to stored exemplars from other categories (e.g., cats, horses, trees, furniture, cars, etc.). Recognition depends on comparing the test item with all stored exemplars so that recognition probability increases with the overall similarity of the test item to all stored exemplars across all categories. Thus, a particular dog would be recognized as having been previously encountered if its similarity to all stored exemplars is high enough to pass a person's criterion for responding old rather than new.

Single-system exemplar models can account for aspects of the neuropsychological results originally interpreted within the multiple-systems perspective (for a summary and continuation of this debate, see Knowlton, 1999; Nosofsky \& Zaki, 1999). Nosofsky and Zaki (1998) have recently shown that an exemplar-based model can successfully simulate the pattern of spared categorization and impaired recognition exhibited by amnesic patients (Knowlton \& Squire, 1993). Amnesic performance was simulated by varying a sensitivity parameter that controls discrimination among exemplars. As has been observed for amnesia, decreased sensitivity led to poorer recognition memory without significantly impairing categorization. Similarly, amnesics' pattern of spared artificial grammar learning and impaired recognition memory has been simulated with a single-system connectionistnetwork (Kinder $\&$ Shanks, 2001). Thus, multiple systems may not be necessary to account for neuropsychologicaldissociations between categorization and recognition. On the other hand, the multiple-systems perspective seems more consistent with functional neuroimaging results showing that visual categorization is associated with activity in visual cortical regions not typically related to declarative memory (Reber et al., 1998a, 1998b).

Research using event-related brain potentials (ERPs) can provide information that is relevant to understanding the relationship between categorization and recognition. Scalp-recorded ERPs are obtained by averaging electroencephalogram(EEG) activity across multiple trials that are designed to engage specific cognitive processes. By time-locking the average to stimulus onset, ERPs reflect the activity of brain processes that are regularly associated with stimulus processing under the experimental conditions of interest. ERPs can be differentiated on the basis of their timing (with millisecond resolution) and scalp distribution, so different neurocognitive processes can be identified with distinct spatiotemporal voltage patterns. Previous studies have examined ERPs in categorization and recognition tasks, so we will review the main findings relevant to each.
Several studies have indicated that ERP effects related to the categorization of visual objects are observed within $200 \mathrm{msec}$ of stimulus onset. The N1 is a negative polarity ERP component, peaking between 150 and $200 \mathrm{msec}$ over posterior head locations, that is thought to reflect visual discrimination processes (e.g., Vogel \& Luck, 2000). Tanaka, Luu, Weisbrod, and Kiefer (1999) used a category verification task in which a category label referring to superordinate (e.g., ANIMAL), basic (e.g., BIRD), or subordinate (e.g., ROBIN) levels was followed by a picture and subjects responded true or false, according to the correspondence between the label and the picture. The N1 was more negative for subordinate than for basic level classification. Tanaka et al. interpreted the N1 enhancement as reflecting increased visual analysis associated with subordinate classification. The $\mathrm{N} 1$ has been observed to be more negative for pictures of objects from natural than from artifactual categories (Kiefer, 2001). Assuming that perceptual information is more important for categorizing natural (e.g., different birds or dogs look somewhat similar) than artifactual (e.g., different tools or pieces of furniture look dissimilar) object categories, Kiefer also attributed the ERP effect to perceptual-processing differences. Another recent study has shown that the N1 is enhanced when experts categorize objects within their domain of expertise (Tanaka \& Curran, 2001). Tanaka and Curran labeled the expertise-sensitive ERP component $N 170$ because of its similarity to the N1 component that numerous studies have found to be greater in response to faces than to other objects (e.g., Bentin, Allison, Puce, Perez, \& McCarthy, 1996; Bentin \& Deouell, 2000; Bötzel, Schulze, \& Stodieck, 1995; Eimer, 1998, 2000a, 2000b; George, Evans, Fiori, Davidoff, \& Renault, 1996; Rossion, Campanella, et al., 1999).

In contrast to the early occurring ERP effects related to categorization, numerous studies have suggested that ERP effects relevant to recognition memory do not begin until 300-400 msec after stimulus onset. In a typical recognition memory experiment, subjects study a list of stimuli (words, pictures, etc.), followed by a test list containing a mixture of old (studied) and new (nonstudied) stimuli. When ERPs are recorded during the test list, electrophysiological differences between correctly classified old and new conditions emerge after about $300 \mathrm{msec}$. The number of component processes underlying such ERP old/new effects and their functional significance remain uncertain. Two recent reviews have suggested that ERP old/new effects can be broken into at least three different subcomponents (Friedman \& Johnson, 2000; Mecklinger, 2000), and this division corresponds well to results from our own laboratory (Curran, 1999, 2000; Curran, Schacter, Johnson, \& Spinks, 2001): FN400 effects, parietal effects, and late frontal effects. The present study is most relevant to the FN400 and parietal old/new effects, so they will be discussed in more detail.

The FN400 old/new effect involves an N400-like component that is more negative for new than for old stimuli over frontal electrode sites between 300 and $500 \mathrm{msec}$ 
(called the "frontal old/new effect" by Mecklinger, 2000, and the "left medial prefrontal episodic memory effect" by Friedman \& Johnson, 2000). The standard N400 component is best studied in psycholinguistic research suggesting that it indexes semantic integration (Kutas \& Iragui, 1998; Kutas \& Van Petten, 1994). The FN400 nomenclature is used here to denote the observation that this old/new effect is often more frontally distributed than is the centro-parietal N400 typically observed in studies of language, although many recognition studies of recognition memory and word repetition have observed centroparietal N400 old/new effects (e.g., Besson, Kutas, \& Van Petten, 1992; Rugg \& Nagy, 1989; Smith \& Halgren, 1989; Van Petten, Kutas, Kluender, Mitchiner, \& McIsaac, 1991). It is unclear whether the N400 and the FN400 are distinct components, but given their spatiotemporal similarity, it is likely that they share at least some neural generators. ${ }^{1}$ The parietal old/new effect is associated with greater positivity over parietal regions to old than to new items between about 400 and $800 \mathrm{msec}$ (reviewed by Allan, Wilding, \& Rugg, 1998; Friedman \& Johnson, 2000; Mecklinger, 2000). The parietal old/new effect encompasses the P300 ERP component (Spencer, Vila Abad, \& Donchin, 2000).

Several ERP investigators (Curran, 2000; Friedman \& Johnson, 2000; Mecklinger, 2000; Rugg, Mark, et al., 1998) have suggested that the FN400 and parietal old/new effects are related to the separate processes of familiarity and recollection posited within dual-process theories of recognition memory (Brainerd, Reyna, \& Kneer, 1995; Hintzman \& Curran, 1994; Jacoby, 1991; Mandler, 1980; Norman \& O'Reilly, 2001). Familiarity is often thought to arise from an assessment of the total similarity between a test item and all study-list information in memory. This conceptualization of familiarity is consistent with the similaritybased matching processes in exemplar models of categorization and recognition (Estes, 1994; Hintzman, 1986, 1988; Medin \& Schaffer, 1978; Nosofsky, 1988, 1991). Recollection is a process that enables the retrieval of specific information about individual items, such as physical attributes or associative/contextual/source information. In one relevant ERP study (Curran, 2000), subjects studied singular and plural nouns (e.g., TABLES, CUP ...), followed by a test list with studied words (TABLES), similar lures that were in the opposite plurality of studied words (CUPS), and completely new words (вОOK). As would be expected of a familiarity process that is merely sensitive to study-test similarity, the FN400 differed between similar (CUPS) and new (BOOK) words, but not between studied words (TABLES) and similar lures (CUPS) that were both highly familiar. As would be expected of a recollection process that enables the retrieval of detailed information, the parietal ERP effect differed between studied (TABLES) and similar (CUPS) items.

The hypothesized correspondence between the FN400 and familiarity is relatively new (reviewed by Friedman \& Johnson, 2000; Mecklinger, 2000), but the relationship between recollection and the parietal ERP old/new effect is more widely accepted. When subjects are asked to introspectively differentiate words specifically remembered from those they merely know to be old, larger parietal old/new effects are associated with remembering than with knowing (Düzel, Yonelinas, Mangun, Heinze, \& Tulving, 1997; Rugg, Schloerscheidt, \& Mark, 1998; Smith, 1993; but see Spencer et al., 2000). The parietal old/new effect is sensitive to variables thought to affect recollection more than familiarity (Paller \& Kutas, 1992; Paller, Kutas, \& McIsaac, 1995; Rugg, Cox, Doyle, \& Wells, 1995). The parietal old/new effect also is associated with the recollection of specific information, such as study modality (Wilding, Doyle, \& Rugg, 1995; Wilding \& Rugg, 1997b), speaker's voice (Rugg, Schloerscheidt, \& Mark, 1998; Wilding \& Rugg, 1996, 1997a), and temporal source (Trott, Friedman, Ritter, \& Fabiani, 1997).

In summary, previous ERP research has identified at least three distinct ERP effects associated with categorization or recognition. Activity related to visual categorization has been associated with the N1 component (150$200 \mathrm{msec}$ ) that peaks over posterior visual brain areas. Recognition memory has been related to the frontocentral FN400 (300-500 msec) associated with familiarity, as well as with the parietal old/new effect (400$800 \mathrm{msec}$ ) associated with recollection. One might interpret these results as consistent with a multiple-systems view because categorization and recognition are associated with different spatiotemporal patterns of brain activity, but such a conclusion would be premature, because it is overly dependent on interexperiment comparisons.

The primary goal of the present experiment was to directly compare ERPs related to categorization and recognition memory in a single experiment. Subjects were trained to recognize categories (or families) of visually similar novel objects called blobs. Blobs, rather than stimuli such as dot patterns, were used to examine conditions more likely to be relevant to the categorization of real-world objects. After training with a given family of blobs, both recognition and categorization tests were given under identical conditions. Test lists included old blobs from the training list that were in the trained family (old/in), old blobs from the training list that were out of the family (old/out), new blobs that were not training-list exemplars but were in the family (new/in), and new blobs that were out of the family (new/out). Subjects made in/out judgments for categorization tests and old/new judgments for recognition tests.

Predictions were derived from the ERP research reviewed above. Given previous evidence that the N1 is enhanced by experience with certain object categories (Tanaka \& Curran, 2001), we predicted that the N1 would be enhanced for blobs that were in trained families, relative to those that were out of trained families. We did not expect old/new effects on the N1, because old/new effects are not typically observed so early in recognition memory studies. Given previous evidence that the parietal old/new effect is related to the recollection of specific information, we predicted that it would show standard old/new effects, but no family membership effects. The FN400 was predicted to 
show in/out effects because previous research has suggested that the FN400 varies with the similarity between studied and tested items (Curran, 2000; Nessler, Mecklinger, \& Penney, 2001) and similarity should be higher for blobs from within the trained family. The FN400 old/ new predictions were less certain. Curran (2000) showed that the FN400 does not discriminate between studied items and highly similar lures (e.g., opposite plurality words). The blob lures are highly similar in the present experiment, but possibly not as similar as plurality-reversed lures. Furthermore, the small number of trained items (eight per family) and larger number of training repetitions (10 per item) may foster more highly differentiated encoding of the items (e.g., Shiffrin \& Steyvers, 1997). Finally, we had no basis for predicting that the ERP old/ new or in/out effects would vary between recognition and categorization tasks. The FN400 and parietal old/new effects for words did not differ when a recognition test was compared with a lexical decision task (Curran, 1999), so we did not expect task differences on these old/new effects in the present experiment.

\section{EXPERIMENT 1}

\section{Method}

\section{Subjects}

The subjects were 37 right-handed students from Case Western Reserve University, who participated for pay ( $\$ 10$ per hour). Twenty-four subjects were included in the final analyses. ${ }^{2}$ Each of the final 24 subjects completed two 2-h sessions on separate days.

\section{Stimuli}

The stimuli were computer-generated, two-dimensional polygons called blobs (see Figure 1). Twelve blob families were constructed by creating a prototype and making family members that were distortions of the prototype. Prototypes were created by dividing a circle into a specified number of vertices (range $=10-28, M=16.83$ vertices per prototype). The possible distance of each vertex from the origin could fall within a specified range of the original circle's radius (range $=30 \%-70 \%, M=53.33 \%$ ). An actual radius was randomly selected within the specified range of each vertex. Once the distances of the vertices were specif ied, they were interconnected to form a closed polygon. Exemplars (i.e., family members) were created around each prototype by randomly changing the radius of the vertices $\pm 20 \%$ from the prototype. Sixteen exemplars were created around each prototype. Four exemplars were in/old items that appeared in the training list and both test lists. The other 12 blobs were in/new items that appeared only on the test lists ( 6 per test list). Blobs from out of the trained families were constructed by creating new prototypes that were matched to each in blob according to the number and distance of the vertices. Each out blob was its own prototype, so out blobs did not form distinctive families (Figure 1, bottom row). Each blob family and its matched out blobs had a unique color. All blobs fit within a circle approximately $4.5 \mathrm{~cm}$ in diameter, subtending a visual angle of approximately $3.22^{\circ}$ when viewed from the subject's distance of $80 \mathrm{~cm}$. Stimuli were presented on a 15-in. Apple Multiscan Color Monitor.

\section{Design and Procedure}

All variables were manipulated within subjects in a task (categorization, recognition) $\times$ family membership (in, out) $\times$ old $/$ new design. Old blobs were presented on the training list, and new blobs were not. In blobs were members of the trained family, and out blobs were not family members. The subjects completed 12 experimental blocks ( 6 per session). A practice training set was given at the beginning of the first session. Sessions were run on separate days $(M=$ 1.38 , range $=0-6$ days intervening between sessions). Each block included training and test phases for a different set of blobs. During each block, the subjects were trained to categorize members of one particular family of blobs. After training, the subjects completed a categorization test and a recognition test. EEG was recorded during the test lists. Blob color was varied between blocks to minimize interblock interference, but color was held constant within each block so it could not be used as a basis for discrimination.

Training began by showing the subject the prototype of one blob family for $10 \mathrm{sec}$. Next, the subjects were given a training list in which four exemplars from in the family were intermixed with four exemplars from out of the family. Each blob was repeated 10 times within the training phase (80 total trials). Repetitions were spaced so that each blob was presented once within Trials 1-8, 9-16, and so forth. Blobs were randomly ordered within each set of 8 trials.

Each training trial started with a central fixation cross for $200 \mathrm{msec}$, followed by the blob for $2,000 \mathrm{msec}$, followed by the instruction to "please respond" for $1,000 \mathrm{msec}$. The intertrial interval

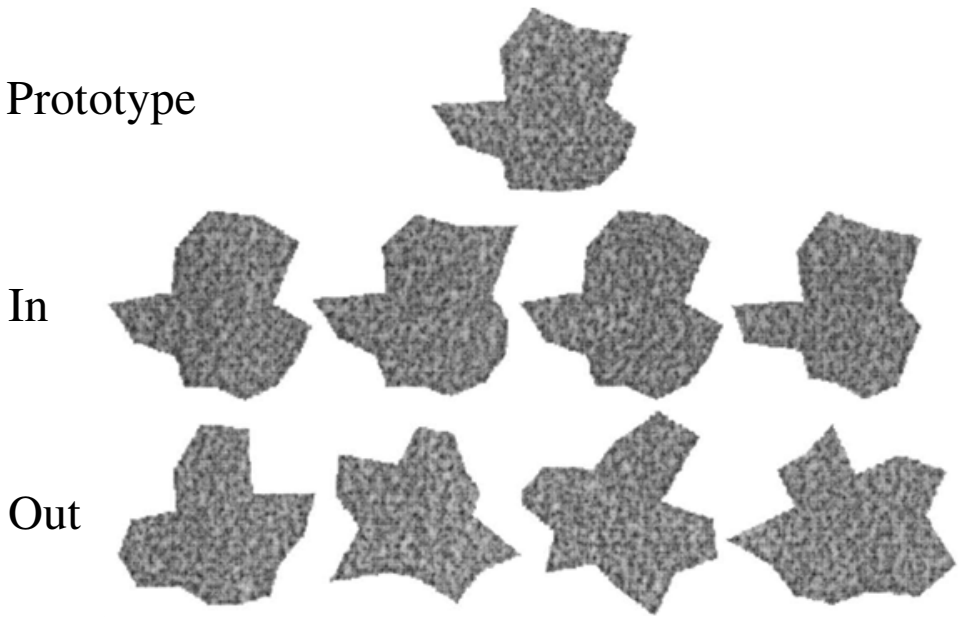

Figure 1. Examples of blob stimuli. The prototype for a single family is shown along with training set exemplars that were in or out of the family. 
was $500 \mathrm{msec}$. The subjects were instructed to press a key for any blobs they considered to be in the family and to not respond to blobs that were out of the family. Responses were recorded only during the 1-sec "please respond" interval. A computer beep sounded after each error (false alarms to out blobs or misses to in blobs). The subjects were given a self-paced rest break between Trials 40 and 41 .

After each training list, the subjects completed two test lists. Training and test lists were separated by a period of at least 2 min for Sensor Net adjustment. Each test list contained the following number of blobs in each condition: four in/old, six in/new, four out/old, six out/new. Pilot testing indicated that false alarm rates were high in the recognition task because of lure similarity, so the design included more new than old items to obtain a sufficient number of accurate trials in all conditions. Each trial consisted of a fixation circle (randomly varying from 500 to $1,000 \mathrm{msec})$, the test blob $(2,000 \mathrm{msec})$, and a question mark that was displayed until the subject responded. The subjects responded with the first two fingers of their right hands and were told to withhold their responses until the question mark appeared. The delayed response procedure was used to minimize response-related ERP differences between the two test tasks. Upon responding, the subjects saw a central square during the 1,000-msec intertrial interval.

For recognition tests, the subjects pressed an old key for any blobs they remembered seeing in the training set or a new key for any blobs not in the training set. They were told to disregard family membership and were warned that the new blobs would be highly similar to those in the training set. For categorization tests, the subjects pressed an in key for any blobs that were members of the trained family and an out key for blobs that were not family members. They were told to disregard old/new status. The order of the test lists was counterbalanced so that categorization occurred on the even-numbered blocks for half the subjects and on the odd-numbered blocks for the other half. The same old blobs were tested in both the recognition and the categorization tests, but new blobs were different in each test. The subjects responded with the first two fingers of the right hands, and assignment of keys to responses was counterbalanced across subjects.

\section{EEG/ERP Methods}

Scalp voltages were collected with a 128-channel Geodesic Sensor Net (Tucker, 1993) connected to an AC-coupled, 128-channel, high input impedance amplifier (200 M $\Omega$; Net Amps, Electrical Geodesics, Eugene, OR). Amplified analog voltages (0.1-100 Hz bandpass, $-3 \mathrm{~dB}$ ) were digitized at $250 \mathrm{~Hz}$. Individual sensors were adjusted until impedances were less than $50 \mathrm{k} \Omega$.

Trials were discarded from analyses if they contained eye movements (vertical EOG channel differences greater than $70 \mu \mathrm{V}$ ) or more than five bad channels (changing more than $100 \mu \mathrm{V}$ between samples or reaching amplitudes over $200 \mu \mathrm{V}$ ). ERPs from individual channels that were consistently bad for a given subject were replaced using a spherical interpolation algorithm (Srinivasan, Nunez, Silberstein, Tucker, \& Cadusch, 1996). The median number of excluded channels/subject was $1.00(M=1.42$, mode $=1$, range $=0$ to 5$)$. Subjects with fewer than 20 good trials in any condition were removed from the final analyses ( $n=5$, as specified in note 2$)$. Across all subjects and conditions, the mean number of acceptable trials per condition per subject was 51.96 (range $=26-72$ ).

ERPs were baseline corrected with respect to a 100 -msec prestimulus recording interval and were digitally low-pass filtered at $40 \mathrm{~Hz}$. An average-refe rence transformation was used to minimize the effects of reference site activity and accurately estimate the scalp topography of the measured electrical fields (Bertrand, Perin, \& Pernier, 1985; Curran, Tucker, Kutas, \& Posner, 1993; Dien, 1998; Lehman \& Skrandies, 1985; Picton, Lins, \& Scherg, 1995; Tucker, Liotti, Potts, Russell, \& Posner, 1994). Average-referenced ERPs are computed for each channel as the voltage difference between that channel and the average of all the channels. Mastoid-referenced ERP plots from representative locations from the International 10-20 system (Jasper, 1958) are presented in the Appendix to facilitate comparison with results from other laboratories.

\section{Results}

\section{Behavioral Results}

The mean proportion correct from each condition is shown in Table 1 . A task (recognition, categorization) $\times$ family (in, out) $\times$ old/new repeated measures analysis of variance (ANOVA) revealed several significant effects. All main effects were significant (categorization $>$ recognition, out $>$ in, old $>$ new, all $p$ s $<.001)$. All interactions except for the task $\times$ old/new interaction $(F<1)$ were significant, culminating in a significant task $\times$ family $\times$ old $/$ new interaction $\left[F(1,23)=90.65, M S_{\mathrm{e}}=0.004, p<\right.$ $.001]$. Both recognition and categorization accuracy were lowest for new blobs that were in trained families. For blobs that were out of the trained families, performance was similar in all conditions, except for the recognition of old blobs being lower than the others.

Reaction time (RT) measures were likely to be insensitive because the subjects withheld their responses until the test blob disappeared ( $2 \mathrm{sec}$ after blob onset). Although failure to observe RT differences between conditions may be attributable to delayed responding, significant RT differences may be meaningful. An ANOVA showed significant main effects of family $\left[F(1,23)=4.42, M S_{\mathrm{e}}=4,047, p<\right.$ $.05]$ and old/new $\left[F(1,23)=7.65, M S_{\mathrm{e}}=2,231, p<.05\right]$. The subjects responded faster to blobs that were in than out of trained families, and faster to old than to new blobs. A significant task $\times$ family interaction $[F(1,23)=11.98$, $\left.M S_{\mathrm{e}}=2,439, p<.01\right]$ indicated that family RT differences were observed only within the categorization task. Thus, despite the requirement to withhold responses, RT was meaningfully affected by the experimental conditions.

\section{ERP Results}

N1 results. N1 analyses were conducted on ERPs averaged across all artifact-free trials. Both correct and incorrect trials were included because large accuracy differences between recognition and categorization could obscure task-related differences on N1 amplitude.

$\mathrm{N} 1$ analyses focused on scalp regions where the N1 amplitude was maximal (most negative). The N1 peaked

Table 1

Mean Accuracy and Reaction Time (RT, in Milliseconds) in Experiment 1

\begin{tabular}{|c|c|c|c|c|}
\hline & \multicolumn{2}{|c|}{ In } & \multicolumn{2}{|c|}{ Out } \\
\hline & Old & New & Old & New \\
\hline \multicolumn{5}{|c|}{ Categorization } \\
\hline$p($ correct $)$ & .93 & .77 & .92 & .90 \\
\hline RT & 2,369 & 2,393 & 2,427 & 2,423 \\
\hline \multicolumn{5}{|c|}{ Recognition } \\
\hline$p($ correct $)$ & .88 & .52 & .77 & .91 \\
\hline RT & 2,403 & 2,434 & 2,401 & 2,425 \\
\hline
\end{tabular}




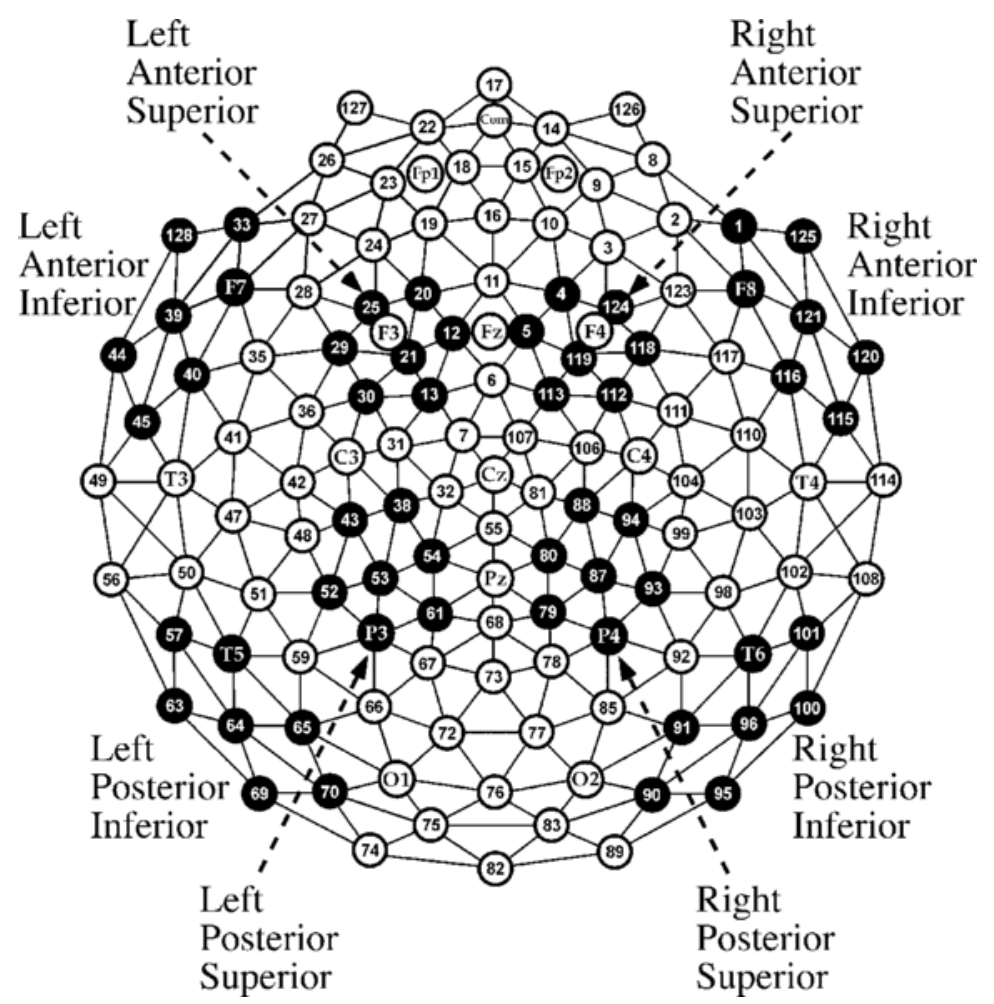

Figure 2. Approximate channel locations on the Geodesic Sensor Net. Locations from the International 10-20 system are shown for reference. The eight clusters of black channels depict the locations used for analyses (right/ left $\times$ anterior/posterior $\times$ inferior/superior).

within a left-hemisphere region including channels $\mathrm{T} 5$, $57,63,64,65,69$, and 70 and a right-hemisphere region including channels T6, 90, 91, 95, 96, 100, and 101 (see the posterior, inferior regions in Figure 2). Mean ERP amplitude will be the primary dependent measure in all analyses, but initial latency analyses were conducted for two reasons: (1) to assess the extent to which amplitude differences between conditions may be compromised by latency differences and (2) to estimate the temporal window in which amplitude analyses should be conducted. Peak latencies were identified as the time at which the N1 was most negative for each subject within each condition (from 100 to $236 \mathrm{msec}$ after stimulus onset). The peak latencies were entered into a task (recognition, categorization) $\times$ family (in, out) $\times$ old $/$ new $\times$ hemisphere repeated measures ANOVA. The only significant effect was a family $\times$ old/new interaction $\left[F(1,23)=12.55, M S_{\mathrm{e}}=56.95, p<\right.$ .01]. N1 latency for old items was shorter for blobs that were in $(184 \mathrm{msec})$ than for those that were out $(188 \mathrm{msec})$ of the trained families, but N1 latency for new items did not vary with family membership (in $=187 \mathrm{msec}$, out $=$ $186 \mathrm{msec})$. Although reliable, these differences appear too small (i.e., $4 \mathrm{msec}=1 \mathrm{EEG}$ sample) to compromise the amplitude analyses.

Amplitude analyses were conducted within a 156$220 \mathrm{msec}$ window that was defined around the overall mean N1 latency of $186 \mathrm{msec}$ (rounded to the nearest 4msec sample). The upper and lower bounds were selected to be two standard deviations (one $S D=16 \mathrm{msec}$ ) above and below the mean. The mean amplitudes within the temporal interval were entered into a task (recognition, categorization) $\times$ family (in, out) $\times$ old $/$ new $\times$ hemisphere repeated measures ANOVA. The only significant effect was the main effect of family membership $[F(1,23)=16.41$, $\left.M S_{\mathrm{e}}=0.70, p<.001\right]$. As is shown in Figure 3, the N1 was enhanced (more negative) for family members (mean amplitude, in $=-2.17 \mu \mathrm{V}$, out $=-1.82$ ). No other effects or interactions were significant (all $p \mathrm{~s}>.16$ ).

One particularly important result for understanding the nature of the family membership effect concerns whether it generalized to new blobs that had never before been seen in the experiment. A planned contrast focusing only on new blobs verified that $\mathrm{N} 1$ amplitude was more negative for blobs that were in $(-2.13 \mu \mathrm{V})$ than for those that were out of $(-1.76 \mu \mathrm{V})$ the family, $[t(23)=3.96, S E=0.10$, $p<.001]$. A planned contrast focusing only on new blobs verified that $\mathrm{N} 1$ amplitude was more negative for blobs that were in $(-2.13 \mu \mathrm{V})$ than for those that were out of $(-1.76 \mu \mathrm{V})$ the family $\left[F(1,23)=6.89, M S_{\mathrm{e}}=0.92, p<\right.$ .01]. Likewise, the N1 was more negative for old blobs that were in $(-2.20 \mu \mathrm{V})$ than for those that were out of $(-1.89 \mu \mathrm{V})$ the family $\left[F(1,23)=4.66, M S_{\mathrm{e}}=0.92, p<.05\right]$. 


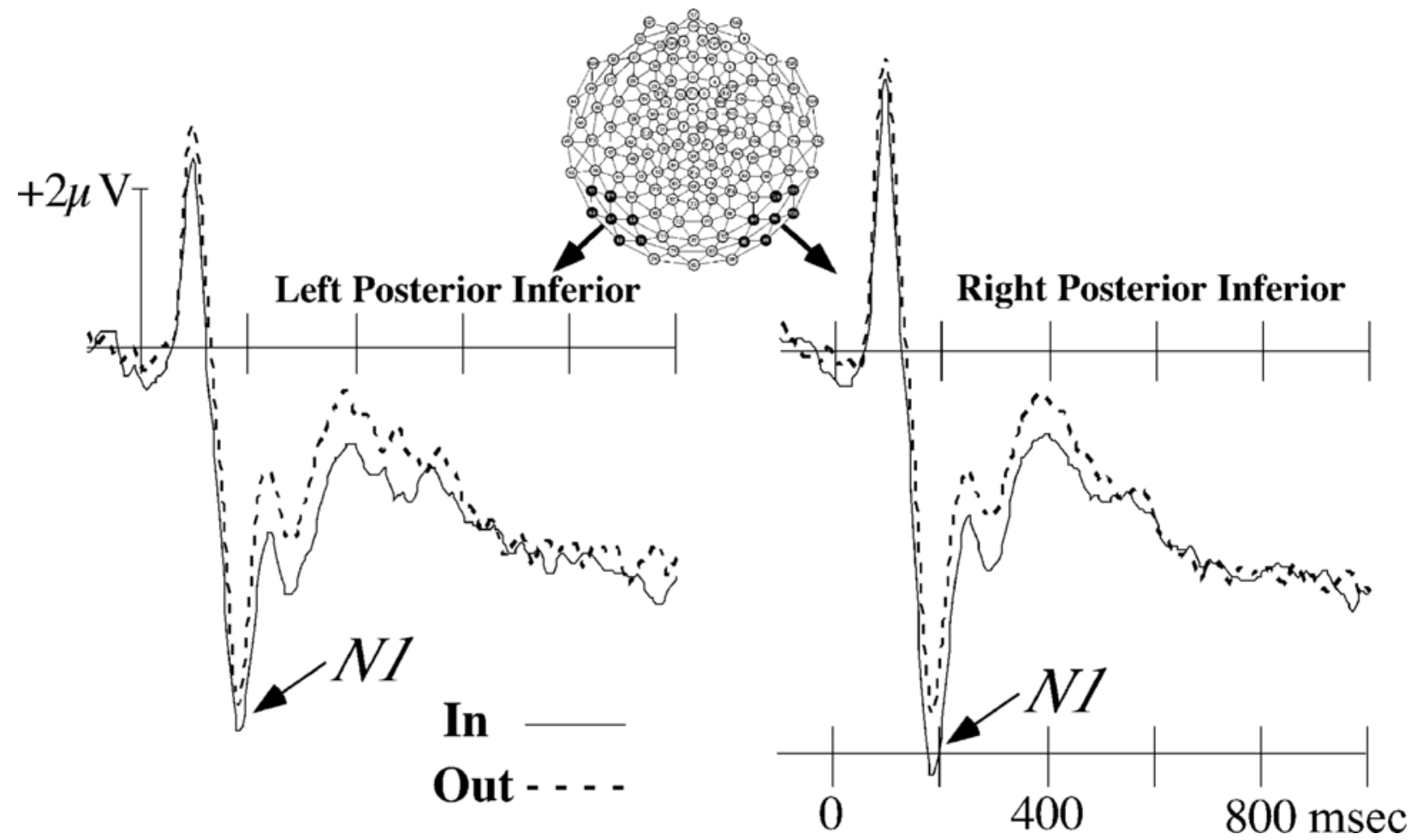

Figure 3. Mean average-referenced ERPs averaged within channels from the left and right posterior inferior regions in Experiment 1 (see Figure 2 for locations). All artifact-free trials are included and averaged across tasks (categorization, recognition) and old/new.

The relative magnitudes of the in/out and old/new differences were compared by computing the relevant differences scores for each subject (averaged across hemispheres). The in/out differences were significantly larger than the old/new differences $[t(22)=2.15, S E=0.11$, $p<.05$, two tailed].

FN400 results. The FN400 (300-500 msec) is typically observed as more negative amplitudes recorded to new than to old items over superior, frontal sites (Curran, 1999, 2000; Friedman \& Johnson, 2000; Guillem, Bicu, \& Debruille, 2001; Mecklinger, 2000; Rugg, Mark, et al., 1998). With the exception of studies from our own laboratory, most of these studies have referenced their recordings to the average of the two mastoid recording sites (channels 57 and 101 in Figure 2). In our own laboratory, using the average-referenced technique, we have found that the FN400 is associated with posterior, inferior (PI) differences (new $>$ old) that have the opposite polarity to the anterior, superior (AS) differences (new $<$ old) that are normally observed. Thus, the present FN400 analyses follow our previous methods of capturing old/new differences over both of these regions (Curran, 1999, 2000).

Curran $(1999,2000)$ has observed the FN400 old/new effect over AS and PI scalp regions between 300 and $500 \mathrm{msec}$. Mean amplitudes are more negative for new than for old items over AS regions, but new items are more positive than old items over PI regions. Thus, with the presently used ERP recording and measurement techniques, the FN400 can be quantified by a crossover interaction between conditions (old, new) and regions (AS, PI). Mean amplitudes (300-500 msec) were entered into a task (recognition, categorization $) \times$ family (in, out) $\times$ old $/$ new $\times$ region $(\mathrm{AS}, \mathrm{PI}) \times$ hemisphere repeated measures ANOVA. The old $/$ new $\times$ region interaction $\left[F(1,23)=4.27, M S_{\mathrm{e}}=\right.$ $2.27, p=.05]$ captured differences consistent with typical FN400 old/new effects (see Figure 4). AS voltages were more negative for new $(-0.53 \mu \mathrm{V})$ than for old $(-0.29 \mu \mathrm{V})$ blobs, but PI voltages were more negative for old $(-0.84 \mu \mathrm{V})$ then for new $(-0.62 \mu \mathrm{V})$ blobs. The family $\times$ region interaction was significant $[F(1,23)=9.80$, $\left.M S_{\mathrm{e}}=1.61, p<.01\right]$. AS voltages were more negative for blobs out of $(-0.57 \mu \mathrm{V})$ than in $(-0.26 \mu \mathrm{V})$ the trained families, but opposite-going differences were observed over PI regions (out $=-0.60 \mu \mathrm{V}$, in $=-0.86 \mu \mathrm{V}$ ). The four-way task $\times$ family $\times$ old $/$ new $\times$ region interaction was difficult to interpret $\left[F(1,23)=4.40, M S_{\mathrm{e}}=1.02, p=.05\right]$. To better understand this interaction, separate ANOVAs were run for each task separately, but they failed to reveal any differences in the pattern of effects shown within each task. The family $\times$ region interaction was significant when each task was considered separately, but no other effects were significant for either task alone. In summary, the FN400 was affected by both family membership and old/new differences.

Parietal results. The spatial distribution of the parietal old/new effect is somewhat different with average-referenced 


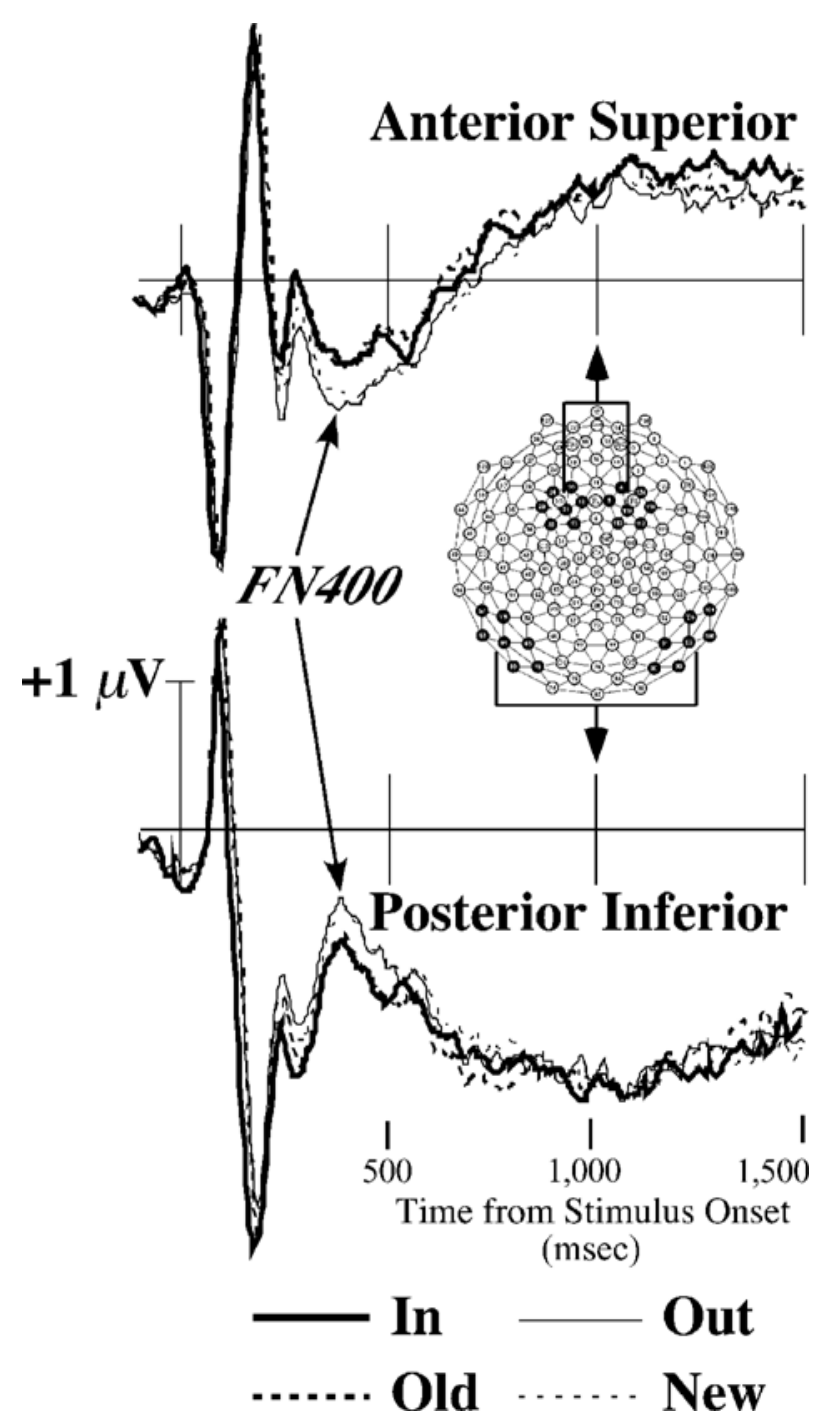

Figure 4. Mean average-referenced ERPs averaged within channels from the anterior, superior and posterior, inferior regions in Experiment 1 (see Figure 2 for locations). All artifactfree trials are included and averaged across tasks (categorization, recognition) and hemispheres.

ERPs than is typically observed with mastoid-referenced ERPs (as has already been explained with regard to the FN400). Relative to a mastoid reference, parietal ERPs (posterior, superior [PS] scalp regions) are more positive for old than for new conditions between about 400 and 800 msec (Friedman \& Johnson, 2000; Mecklinger, 2000; Rugg, 1995). The average-reference captures these PS differences (old $>$ new), as well as opposite polarity differences (old $<$ new) over anterior, inferior (AI) regions (Curran, 1999, 2000; Curran et al., 2001). Thus, condition (old, new) $\times$ region $(\mathrm{PS}, \mathrm{AI})$ interactions are indicative of the parietal old/new effect.

Mean amplitudes (400-800 msec) were entered into a task (recognition, categorization $) \times$ family (in, out $) \times$ old $/$ new $\times$ region $(\mathrm{PS}, \mathrm{AI}) \times$ hemisphere repeated measures ANOVA. The old/new $\times$ region interaction was significant $\left[F(1,23)=7.20, M S_{\mathrm{e}}=0.84, p<.05\right]$. PS voltages were more positive for old $(2.04 \mu \mathrm{V})$ than for new $(1.89 \mu \mathrm{V})$ blobs, but AI voltages were more negative for old $(-1.32 \mu \mathrm{V})$ than for new $(-1.12 \mu \mathrm{V})$ blobs. The family $\times$ region interaction approached significance $[F(1,23)=$ $\left.3.95, M S_{\mathrm{e}}=1.39, p>.05\right]$. Interestingly, this trend toward a parietal in/out (out $>$ in) effect was of opposite polarity as compared with the parietal old/new (old $>$ new) effect. That is, the parietal effect was larger for the more familiar old items within the old/new comparison, but it tended to be larger for the less familiar outsiders in the in/out comparison.

Although the parietal old/new effect was statistically significant, it was somewhat weaker than is typically observed. However, the parietal old/new effect usually is observed with ERPs including only correct trials (hits vs. correct rejections). Therefore, ERPs were recomputed to include only correct trials. Across all subjects and conditions, the mean number of accurate and artifact-free trials per condition per subject was 42.88 (range $=20-69$ ). Again, the in/out $\times$ region interaction was not significant $\left[F(1,23)=3.33, M S_{\mathrm{e}}=1.84, p>.05\right]$. The task $\times$ old/new $\times$ region interaction was significant $[F(1,23)=$ $\left.4.52, M S_{\mathrm{e}}=1.27, p<.05\right]$. Follow-up ANOVAs indicated that the old/new $\times$ region interaction was significant for the recognition task $\left[F(1,23)=7.66, M S_{\mathrm{e}}=1.72, p<\right.$ $.05]$, but not for the categorization task $\left(F<1, M S_{\mathrm{e}}=\right.$ 0.98). As was expected, differences between old and new conditions were larger when only accurate trials on the recognition task were considered (see Figure 5; PS, old $[2.16 \mu \mathrm{V}]>$ new $[1.91 \mu \mathrm{V}]$; AI, old $[-1.52 \mu \mathrm{V}]<$ new $[-1.03 \mu \mathrm{V}])$. These differences are still somewhat small, but this is understandable given the difficulty the subjects experienced discriminating old blobs (hit rate $=88 \%$ ) from highly similar new blobs (false alarm rate $=48 \%$ ).

Topographic comparisons. In summary of the previous analyses, ERPs were modulated by both family membership and old/new differences. Whereas in/out categorization exerted significant effects on the N1 and FN400 components, old/new recognition influenced the magnitude of the FN400 and parietal effects. Topographic analyses were done to better understand the relationship between the four primary effects: N1 in/out, FN400 in/out, FN400 old/new, and parietal old/new. Might they reflect the activity of a single process (or system) that initially responds to categorical differences and then later discerns differences between studied and nonstudied exemplars? Might each of these effects map onto different neurocognitive processes related to categorization or recognition? Although pinpointing the anatomical location of the neural generators of scalp-recorded ERPs is difficult, different topographic patterns indicate that "the underlying combination of activities at the brain sources must also be different" (Picton et al., 2000, p. 147). Such topographic differences could reflect either different underlying sources or common sources activated with different relative strengths (Alain, 


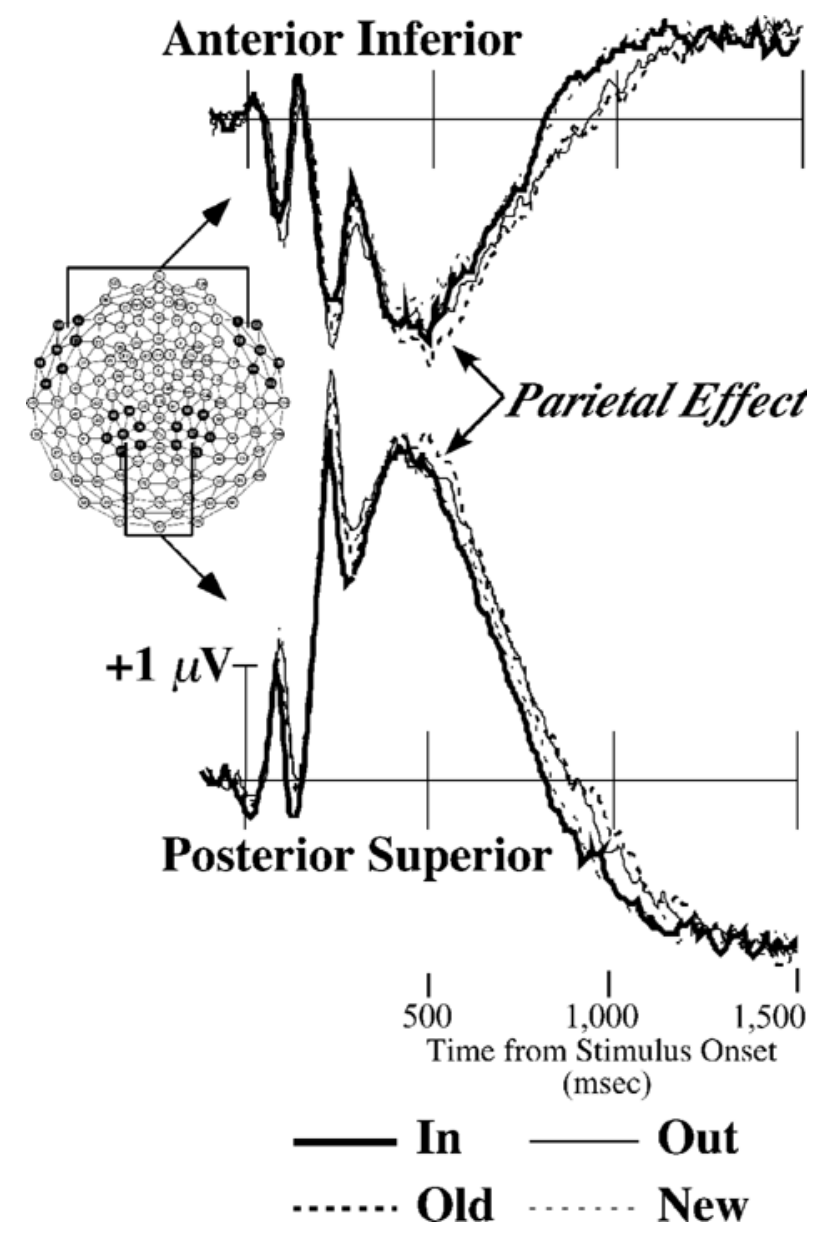

Figure 5. Mean average-referenced ERPs averaged within channels from the anterior, inferior and posterior, superior regions in Experiment 1 (see Figure 2 for locations). ERPs have been averaged across right and left hemispheres. Only correct trials within the recognition task are included.

Achim, \& Woods, 1999). Thus, topographic differences between conditions would be consistent with separate underlying processes, although they could also reflect different patterns of activation across the same processes.

The four primary experimental effects were compared topographically. Figure 6 (left panel) shows topographic maps of the in/out (left) and old/new (right) differences within each temporal window. Mean differences associated with each effect were computed within each of the regions depicted in Figure 2. The differences were normalized prior to analysis, so that differences in the overall magnitude of the effects would not bias the topographic comparisons (following the vector length method of McCarthy \& Wood, 1985).

Four specific questions were addressed through pairwise comparisons of the normalized differences. (1) Is the topography of the $\mathrm{N} 1 \mathrm{in} / \mathrm{out}$ effect different from the topography of the FN400 in/out effect? (2) Are the FN400 in/out and old/new effects associated with distinct topographic patterns? (3) Is the topography of the FN400 old/new effect different from the topography of the parietal old/new effect? (4) Is the topography of the $\mathrm{N} 1$ in/out effect different from the topography of the parietal old/ new effect? These questions are addressed in turn.

Is the topography of the $\mathrm{N} 1 \mathrm{in} /$ out effect different from the topography of the FN400 in/out effect (Figure 6, 1A vs. 1C)? Normalized N1 (156-220 msec) and FN400 $(300-500 \mathrm{msec})$ in/out differences were entered into a difference $(\mathrm{N} 1, \mathrm{FN} 400) \times$ hemisphere $\times$ anterior/posterior $\times$ inferior/superior ANOVA. The difference $X$ hemisphere $\times$ inferior/superior interaction was significant $[F(1,23)=$ $\left.4.53, M S_{\mathrm{e}}=0.02, p<.05\right]$. The interaction captured the fact that the N1 and the FN400 in/out differences had similar relative magnitudes over superior scalp regions but, over inferior regions, the $\mathrm{N} 1$ difference was larger over the right hemisphere (see Figure 3) and the FN400 difference was larger over the left hemisphere. Although topographic differences between the N1 and the FN400 in/out effects were significant, visual inspection of Figure 6 reveals broadly similar topographic patterns. ${ }^{3}$

Are the FN400 in/out and old/new effects associated with distinct topographic patterns (Figure 6, 1C vs. 1D)? Normalized in/out and old/new mean differences were calculated within the temporal window of the FN400 $(300-500 \mathrm{msec})$ and were entered into a difference (in/out, old/new) $\times$ hemisphere $\times$ anterior/posterior $\times$ inferior/ superior ANOVA. No effects were significant, so this analysis provided no indication of topographic differences between the FN400 in/out and the FN400 old/new effects.

Is the topography of the FN400 old/new effect different from the topography of the parietal old/new effect (Figure $6,1 \mathrm{D}$ vs. 1F)? Normalized FN400 (300-500 msec) and parietal (400-800 msec) old/new differences were entered into a difference $(\mathrm{FN} 400$, parietal $) \times$ hemisphere $\times$ anterior/posterior $\times$ inferior/superior ANOVA. The fourway difference $X$ hemisphere $X$ anterior/posterior $X$ inferior/superior interaction was significant $[F(1,23)=$ $\left.4.88, M S_{\mathrm{e}}=0.01, p<.05\right]$. The primary difference between these temporal intervals is the presence of left-PS (old $>$ new) and right-AI (old $<$ new) differences associated with the parietal, but not with the FN400 old/new effect. Overall, the 400-800 msec topography was somewhat different than the typical parietal old/new effect. In particular, it was dominated by a medial frontal old $>$ new difference that originated around $200 \mathrm{msec}$ and lasted until approximately 1,400 msec after stimulus onset. It appears to overlap with the AS aspect of the FN400 but is closer to the frontal poles than is the typical FN400. Similarly distributed, long-duration, frontal old/new effects have been previously described in studies of recognition memory but are poorly understood (reviewed by Friedman \& Johnson, 2000). In the present experiment, this frontal old/new effect clearly increased the similarity of the 300500 and $400-800 \mathrm{msec}$ topographies. Despite these visual similarities, the old/new effect was associated with statis- 


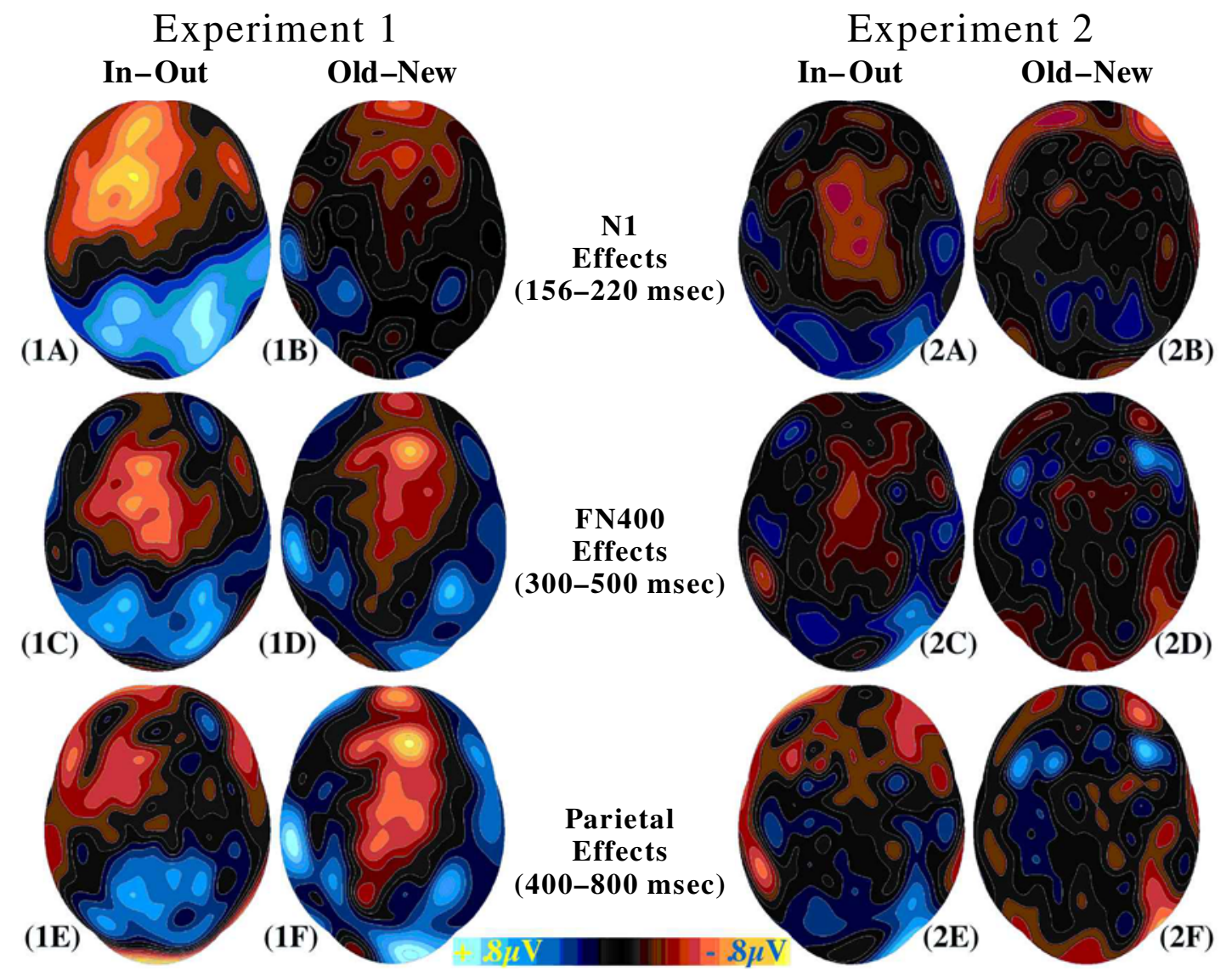

Figure 6. Topographic distributions of the ERP in-out and old-new differences within the three temporal windows analyzed in Experiments 1 (left panel) and 2 (right panel). All artifact-free trials are included and averaged across tasks.

tically different topographies during the FN400 effect $(300-500 \mathrm{msec})$ and the parietal effect $(400-800 \mathrm{msec})$ intervals (replicating Curran, 1999, 2000).

Is the topography of the $\mathrm{N} 1 \mathrm{in} /$ out effect different from the topography of the parietal old/new effect (Figure 6, 1A vs.1F)? Normalized N1 in/out (156-220 msec) and parietal old/new (400-800 msec) differences were entered into a difference $(\mathrm{FN} 400$, parietal $) \times$ hemisphere $\times$ anterior/ posterior $\times$ inferior/superior ANOVA. The difference $\times$ anterior/posterior $\left[F(1,23)=5.96, M S_{\mathrm{e}}=0.25, p<.05\right]$ and four-way difference $\times$ hemisphere $\times$ anterior/posterior $\times$ inferior/superior $\left[F(1,23)=6.93, M S_{\mathrm{e}}=0.04, p<.01\right]$ interactions were significant. These topographic differences can be seen by comparing $1 \mathrm{~A}$ and $1 \mathrm{~F}$ in Figure 6.

\section{EXPERIMENT 2}

Experiment 1 indicated that the N1 and the FN400 were sensitive to categorical differences among the stimuli (in/out effects) and that the FN400 and parietal effects were sensitive to recognition-related differences (old/new effects). Thus, we have some evidence for electrophysiologicaldifferences between category-related and recognition-related processes. Old/new differences can be unambiguously at- tributed to memory for the training set, because appearance on the training list is the only factor that differentiates these items. It is conceivable, however, that categorical differences are more stimulus related and not necessarily dependenton memory for the training experience. By definition, the family members are structurally more similar to one another than are the outsiders. Thus, in/out differences could be a product of similarity effects within the test lists themselves. For example, short-term priming effects may occur when two family members are presented in succession. ERP differences between recognition and categorization would be considerably less interesting if only recognition effects were the product of memory for the training set. Relevant behavioral evidence has shown that prior training with category exemplars is not necessary for above-chance categorization of novel dot patterns (Palmeri \& Flanery, 1999). In fact, Palmeri and Flanery showed that subjects who were tested in the absence of category training performed much like amnesic patients in showing accurate categorization performance but chance recognition.

Experiment 2 tested the possibility that effects observed in Experiment 1 did not depend on category training by omitting the training task but otherwise replicating the method in Experiment 1. 
Table 2

Mean Accuracy and Reaction Time (RT, in Milliseconds) in Experiment 2

\begin{tabular}{lccccc}
\hline & \multicolumn{4}{c}{ Categorization } \\
\cline { 2 - 6 } & \multicolumn{3}{c}{ In } & & Out \\
\cline { 2 - 6 } & Old & New & & Old & New \\
\hline$p$ (correct) & .77 & .76 & & .72 & .71 \\
RT & 2,694 & 2,686 & & 2,706 & 2,711 \\
\hline
\end{tabular}

\section{Method}

\section{Subjects}

The subjects were 28 right-handed students from the University of Colorado at Boulder, who participated for introductory psychology credit. Twenty-four subjects were included in the final analyses. ${ }^{4}$

\section{Stimuli, Design, and Procedure}

Apart from the following exceptions, Experiment 2 replicated the method in Experiment 1 in all major respects, except that the training phase was omitted from Experiment 2.

Experiment 2 was run in one session instead of two, because omitting the training phase reduced the overall length of the experiment considerably. As in Experiment 1, two test lists were given for each family of blobs. Unlike Experiment 1, in which one test list was categorization and one was recognition, categorization was tested in both lists in Experiment 2. Recognition testing would make no sense in the absence of a study/training list. The subjects were instructed that they needed to try to discover the structure of the family during the test blocks. No feedback was provided.

\section{Results}

Given the hypothesis that the ERP in/out and old/new differences observed in Experiment 1 were attributable to training, we predicted no such differences in Experiment 2. Because the training set was omitted from Experiment 2, the old/new variable is not truly meaningful in the present experiment. However, it was retained in all analyses to assess the possibility that the Experiment 1 old/new differences were attributable to stimulus confounds because old and new blobs were not counterbalanced in Experiment 1 . Thus, old blobs are those that would have been presented in training if the training lists had actually been presented. One true difference between old and new blobs in Experiment 2, however, is that old blobs were presented in each of the two test lists for each family, but new blobs were presented only in one test list.

\section{Behavioral Results}

Mean accuracy and RT is shown in Table 2. Categorization accuracy was above chance in all conditions. Thus, the subjects were able to learn to differentiate between family members and outsiders without training and within the confines of the test lists. Accuracy was considerably lower in Experiment 2 than in Experiment 1, with the exception of new family members that the subjects categorized at similar levels in each experiment. In Experiment 2, accuracy was uniformly low in all conditions, but Experiment 1 accuracy fell in the in/new condition. Although the subjects in Experiment 1 learned the blob families more thoroughly because of training, they were more likely to be duped by the within-experiment novelty of the new blobs. This would not be a factor in Experiment 2, in which old and new blobs did not truly differ (because old blobs were not seen in a previous training phase).

The subjects were consistently slower in Experiment 2 than in Experiment 1. This is consistent with the fact that the subjects had to learn the category structure within the test lists in Experiment 2.

\section{ERP Results}

As was predicted, none of the in/out or old/new effects observed in Experiment 1 were replicated when training was omitted from Experiment 2. Relevant analyses are presented below. Only topographic differences are shown (Figure 6, right panel), because they can be easily compared against the corresponding differences from Experiment 1 (Figure 6, left panel).

N1 results. N1 analyses again focused on the PI regions shown in Figure 2. Mean amplitudes from 156 to $220 \mathrm{msec}$ were entered into a family (in, out) $\times$ old $/$ new $\times$ hemisphere ANOVA. A similar ANOVA revealed significant in/out differences in Experiment 1. In Experiment 2, N1 amplitude did not significantly differ between the in $(M=-1.22 \mu \mathrm{V})$ and the out $(-1.12 \mu \mathrm{V})$ conditions $\left[F(1,24)=1.33, M S_{\mathrm{e}}=0.36\right]$. Differences between old $(-1.14 \mu \mathrm{V})$ and new $(-1.20 \mu \mathrm{V})$ conditions were also nonsignificant $\left[F(1,24)=.44, M S_{\mathrm{e}}=0.34\right]$. Likewise, no interactions involving the old/new or in/out conditions were significant.

FN400 results. Mean amplitudes $(300-500 \mathrm{msec})$ were entered into a family (in, out) $\times$ old $/$ new $\times$ region (AS, PI; see Figure 2) $\times$ hemisphere repeated measures ANOVA. A condition $\times$ region (AS, PI) interaction in Experiment 1 indicated that the FN400 was significantly influenced by both in/out and old/new differences. Neither effect approached significance in Experiment 2 [old/new $\times$ AS/PI, $F(1,24)=0.08, M S_{\mathrm{e}}=1.04$; in/out $\times$ AS/PI, $\left.F(1,24)=0.97, M S_{\mathrm{e}}=1.23\right]$. No other effects involving the old/new or the in/out conditions were significant.

Parietal results. Mean amplitudes (400-800 msec) were entered into a family (in, out) $\times$ old $/$ new $\times$ region $(\mathrm{PS}, \mathrm{AI}$; see Figure 2) $\times$ hemisphere repeated measures ANOVA. A significant parietal old/new effect was substantiated with an old/new $\times$ regions (PS, AI) interaction in Experiment 1 (400-800 msec). The old/new $\times$ PS/AI interaction did not approach significance in Experiment 2 $\left[F(1,24)=0.00, M S_{\mathrm{e}}=47\right]$. The in/out $\times$ position interaction was also nonsignificant $\left[F(1,24)=0.52, M S_{\mathrm{e}}=\right.$ $1.35]$. No other effects involving the old/new or the in/out conditions were significant.

\section{GENERAL DISCUSSION}

The purpose of the present research was to investigate the relationship between categorization and recognition memory by using ERPs to specify the spatiotemporal dynamics of the underlying brain processes. ERPs related to relatively early visual processes $(\mathrm{N} 1,156-200 \mathrm{msec})$ dif- 
ferentiated between blobs that were members of trained categories (in) and those that were not (out). Middle latency ERPs (FN400 effects, $300-500 \mathrm{msec}$ ) also were sensitive to category membership (in/out) as well as differentiating between old (trained) and new exemplars. Later ERPs (parietal effects, $400-800 \mathrm{msec}$ ) were significantly sensitive only to old/new differences. These effects were observed after the subjects underwent categorical training (Experiment 1) but were not observed in the absence of training (Experiment 2), so the ERP differences can be attributed to memory for the training episode.

The ensuing discussion interprets old/new differences as related to recognition and in/out differences as related to categorization, but one also might expect differences according to whether subjects were actually performing a recognition or a categorization task. For example, a conceptually similar experiment compared categorization and recognition memory of novel dot patterns with fMRI (Reber et al., 1998a). Their primary finding was that activity within the posterior occipital cortex was greater for old than for new patterns in the recognition test but that it was greater for noncategory members than for category members in the categorization task. Thus, occipital activity appeared to increase with familiarity in the recognition task but to decrease with familiarity in the categorization task. Reber et al. (1998a) chose to emphasize task differences when interpreting these opposite polarity differences, but numerous stimulus-related differences could have influenced the comparison also (as was clearly discussed by Reber et al., 1998a). Task-related differences were minimal in the present research when stimuli were equated across tasks.

ERP old/new and in/out differences reveal the activity of brain processes that are capable of underlying categorybased and recognition-baseddiscriminations, respectively. Whether or not such differences interact with task instructions may be related to the automatic/controlled nature of the underlying processes. The lack of task interactions for the $\mathrm{N} 1$ and FN400 effects suggests that these are relatively automatic processes that discriminate between in/out (N1 and FN400) or old/new (FN400) at similar levels regardless of task instructions. The observation that the parietal old/new effect was enhanced when subjects were performing the recognition task, as compared with the categorization task, suggests that it may reflect the activity of a memory process that is more intentionally controlled. Curran (1999) previously observed that neither the FN400 nor the parietal old/new effects were influenced by such task differences when words and pseudowords were given either recognition or lexical decision judgments. Curran's (1999) recognition task was considerably easier than the present task with similar lures, so the present task dependency of the parietal old/new effect may reflect the greater effort needed to discriminate old from new blobs.

\section{N1 Effects}

N1 amplitude was more negative for family members than for outsiders. This is the first demonstration, to our knowledge, that the N1 is sensitive to experimentally induced long-term memory. Previous research has shown that the N1 is sensitive to immediate word repetition (McCandliss, Curran, \& Posner, 1993, 1994; Posner \& McCandliss, 1999). The present research ruled out such short-term influences, because N1 in/out effects were present after categorical training (Experiment 1) but were absent without training (Experiment 2). The N1 did not differentiate between old and new blobs, so it is unlikely to reflect the activity of a process capable of supporting accurate recognition judgments.

The present finding that the N1 may be related to categorization is consistent with previous research (Kiefer, 2001; Tanaka \& Curran, 2001; Tanaka et al., 1999). Tanaka and Curran found that dog and bird experts exhibited an enhanced $\mathrm{N} 1$ when categorizing pictures of objects within their domain of expertise, so N1 amplitude was modulated by differential experience with particular object categories. The present results show that the $\mathrm{N} 1$ is similarly enhanced by moderate amounts of experimental training with categories of visual objects (i.e., families of blobs). Not only was this enhancement observed for the specific exemplars seen in the training phase, but it also generalized to new blob exemplars that were family members. The ability to generalize from previous experience to classify new objects is a fundamental property of categorization, so these results strengthen the hypothesis that the N1 is related to visual categorization.

The N1 is considered to be related to visual identification processes (e.g., Vogel \& Luck, 2000). The present results, along with results from real-world experts, suggest that the underlying identification processes can be shaped by visual experience. These results are consistent with previous fMRI research relating posterior occipital cortex activity to category learning (Reber et al., 1998a, 1998b). Our results add important time course information to these results. Because the N1 takes place at a relatively early stage of information processing, it is likely that categorical experience is influencing initial perceptual identification processes, rather than reflecting later, possibly re-entrant or top-down visual processes.

Tanaka and Curran (2001) speculated that their expertiseenhanced N1 may be related to the N170 component observed in studies of face recognition. The N170 is more negative when subjects view faces than when they view other objects (e.g., Bentin et al., 1996; Bentin \& Deouell, 2000; Bötzel et al., 1995; Eimer, 1998, 2000a, 2000b; George et al., 1996; Rossion, Campanella, et al., 1999). The N170 is typically maximal for faces at mastoid (Bentin \& Deouell, 2000) or T5/T6 (Bötzel et al., 1995; Eimer, 2000b; George et al., 1996; Rossion, Delvenne, et al., 1999; Taylor, McCarthy, Saliba, \& Degiovanni, 1999) locations of the International 10-20 System (Jasper, 1958). These locations fall within the regions where the $\mathrm{N} 1$ was maximal in the present experiment (left and right mastoids are Channels 57 and 101; see Figure 2). The N170 usually peaks around $170 \mathrm{msec}$, but the present $\mathrm{N} 1$ peak $(186 \mathrm{msec})$ is within the range of other published N170 studies with 
faces (e.g., 189 msec, George et al., 1996). Thus, the spatiotemporal distribution of the presently observed N1 is similar to that of the N170 to faces.

\section{FN400 Effects}

The FN400 differentiated blobs on the basis of both category membership (in vs. out of trained families) and exemplar-specific memory (old vs. new). It has been previously argued that the FN400 old/new effect is related to the so-called familiarity component of dual-process theories of recognition memory (Curran, 2000; Friedman \& Johnson, 2000; Mecklinger, 2000; Rugg, Mark, et al., 1998). Although familiarity is a term with several different psychological meanings, Curran (2000) specifically defined familiarity as an assessment of the global similarity between studied and tested items. This sense of familiarity is consistent with the output of exemplar-based models of categorization/recognition (e.g., Estes, 1994; Hintzman, 1986, 1988; Medin \& Schaffer, 1978; Nosofsky, 1991), as well as of several other models of recognition memory (reviewed by Clark \& Gronlund, 1996; e.g., Gillund \& Shiffrin, 1984; Humphreys, Bain, \& Pike, 1989; Murdock, 1982; Shiffrin \& Steyvers, 1997). The sensitivity of the FN400 to both in/out and old/new differences provides converging evidence that a familiarity-like process consistent with these models may exist within the brain.

The FN400 results suggest the existence of a single process contributing to both categorization and recognition memory, and this possibility is supported by the behavioral interactions that were observed. Categorization was more accurate for old and new items, and recognition memory was more accurate for outsiders than for family members. Thus, our behavioral results suggest that processes underlying categorization and recognition must interact at some level to influence decision accuracy. Such interactions may have been obscured in previous neuropsychological studies that have tested categorization and recognition memory under quite different conditions (see Nosofsky $\&$ Zaki, 1999). Dissociations between amnesic and control subjects may be less likely if the tasks were compared under otherwise identical conditions, as in the present study.

The FN400 results clearly show that a process sensitive to categorical differences between stimuli can also differentiate between old and new exemplars, but the N1 was sensitive only to category membership, and not to old/new differences. Why would categorization and recognition be dissociated early on (N1) but associated at later stages of processing? One possibility is that the N1 reflects purely visual aspects of memory that are sufficient for categorizing the blobs (on the basis of visual similarity to trained categories) but insufficient for recognizing particular exemplars. The FN400, on the other hand, reflects a later state of processing that is likely to draw on different sorts of information to assess the overall similarity between training and test items. Assuming that the FN400 is related to the N400 that is often observed in ERP studies of language comprehension (Kutas \& Iragui, 1998; Kutas \&
Van Petten, 1994), it would be sensitive to semantic information (e.g., Olichney et al., 2000). Other recognition memory research has shown the FN400 to be related to the semantic similarity between old and new items (Nessler et al., 2001). Such semantic information would not necessarily be available to the visual processes underlying the $\mathrm{N} 1$. The blobs used in the present experiment were semantically impoverished, but it is conceivable, for example, that the subjects (who saw each exemplar 10 times during training) used a naming strategy that would foster semantic processing (e.g., the prototype in Figure 1 may remind a subject of Texas).

Both the N1 and the FN400 may reflect cortical processes that are sensitive to stimulus familiarity (i.e., the similarity between a test item and previously stored experiences), but the processes may be sensitive to different types of information. Does this constitute evidence for separate systems? The specific criteria needed for postulation of a memory system are debatable (Schacter \& Tulving, 1994; Sherry \& Schacter, 1987), and a single experiment is unlikely to be sufficient, but aspects of our results seem relevant. We detected significant differences in the topography of the N1 and the FN400 in/out effects, so different neural populations may contribute to these effects. However, as can be seen in Figure 6 (A vs. C), the similarity of these patterns is more conspicuous than any differences, so the present experiment does not provide particularly compelling evidence for the anatomical separability of the underlying processes. Furthermore, the ERP waveforms presented in Figure 4 suggest that the in/out differences are temporally continuous between the N1 and the FN400 epochs.

Even if we were to emphasize the slight topographic differences observed between N1 and FN400 in/out effects, two different systems with such properties are unlikely to account for previously discussed amnesic dissociations between categorization and recognition. Damage to either system would be more likely to impair categorization, whereas it is recognition that is selectively impaired by amnesia. A recent study showed that amnesic patients could discriminate between semantically congruous (babyanimal-cub) and incongruous (water-sport-kitchen) categorical pairs and showed normal N400 differences between congruous and incongruous conditions (e.g., Olichney et al., 2000). Another recent recognition memory experiment has shown that the FN400 old/new effect was normal in an amnesic patient with selective hippocampal damage but the parietal old/new effect was abolished (Düzel, Vargha-Khadem, Heinze, \& Mishkin, 2001). Because the FN400 is spared by amnesia, the underlying processes are unlikely to be the source of amnesic patients' difficulties with recognition memory.

\section{Parietal Effects}

The standard parietal ERP old/new effect was replicated. Previous research has related the parietal old/new effect to the ability to recollect specific information from a previous study episode (Allan et al., 1998; Curran, 2000; Fried- 
man \& Johnson, 2000; Mecklinger, 2000). Several lines of evidence, including ERP studies with amnesic patients (e.g., Düzel et al., 2001) or with intracranially recorded ERPs, have suggested that the hippocampus and/or medial temporal cortex may contribute to the parietal old/ new effect (reviewed by Friedman \& Johnson, 2000; Mecklinger, 2000). Thus, the neural mechanisms underlying the parietal old/new effect may be the same as those damaged to cause neuropsychological dissociations between categorization and recognition memory (Knowlton et al., 1994; Knowlton et al., 1996; Knowlton et al., 1992; Knowlton \& Squire, 1993, 1996; Squire \& Knowlton, 1995).

The multiple memory systems perspective (e.g., Knowlton, 1999) would be bolstered if our results showed that the parietal old/new effect was uniquely related to recognition memory. However, we cannot conclusively rule out the presence of parietal in/out effects in the present experiments. We observed a nonsignificant trend indicating larger parietal voltages for outsider than for family members. Thus, in contrast to the old/new effect in which the parietal effect was larger for the more familiar class of items (old $>$ new), the parietal in/out effect was larger for the less familiar class of items (out $>$ in). These opposite polarity differences are reminiscent of the opposing patterns of fMRI activation observed in comparing categorization and recognition tasks (Reber et al., 1998a). Given the evidence linking the parietal old/new effect to the hippocampus, we doubt that our parietal ERP results are entirely attributable to the posterior occipital areas implicated in Reber et al.'s (1998a) f MRI study, although these areas could contribute to the ERP effects. Other functional imaging research has shown that the polarity of hippocampal activation changes between old and new recognition memory conditions can vary somewhat unpredictably. For example, using very similar PET recognition memory paradigms with novel objects, Schacter and colleagues have found old $>$ new hippocampal activation differences in some experiments (Schacter et al., 1995; Schacter et al., 1997) but new $>$ old differences in others (Heckers et al., 2000; Schacter et al., 1999). Thus, the relationship between stimulus familiarity and hippocampal activity is not entirely straightforward.

\section{Conclusions}

The clearest general result to emerge from the present experiments is a temporal sequence of events involving a transition between early sensitivity to category membership (in/out differences) and later sensitivity to differential experience with particular exemplars (old/new differences). This temporal sequence suggests that the information necessary for categorization may become available earlier than that necessary for recognition memory. These temporal differences should be interpreted cautiously, because ERPs do not provide an exhaustive measure of brain activity, so our methods may be insensitive to earlier recognition-related processes. A more conservative interpretation of our results is that, among the memory-related effects we observed (N1, FN400, and parietal ERP components), categorical sensitivity appeared earlier than recognition-related sensitivity. Even this more conservative interpretation provides important information about the temporal dynamics of the underlying memory effects and their ERP correlates. These empirical time course results are particularly important now that models of categorization are being extended to account for temporal dynamics (Lamberts, 2000; Nosofsky \& Alfonso-Reese, 1999).

One way to conceptualize the temporal transition may be in terms of a shift from a gross level of sensitivity to stimulus similarity (N1 in/out effects) to intermediate levels (FN400 in/out and old/new effects) to fine-grained differences (parietal old/new effects). In the present experiment, categorically different blobs (in vs. out) were more visually dissimilar than old and new blobs. We believe this situation is often true of real-world differences between categorization and recognition memory. For example, cats and dogs are categories that are easy to discriminate visually, as compared with the visually difficult problem of recognizing differences between your sister's dog Fido and your brother's dog Rover. Future research could explore this issue more systematically by contriving situations in which different categories are visually similar, yet recognition discriminations are visually dissimilar.

The present results are generally consistent with the "complementary learning systems" framework recently advanced by O'Reilly and colleagues (McClelland, McNaughton, \& O'Reilly, 1995; Norman \& O'Reilly, 2001; O'Reilly \& Rudy, 2001). According to this framework, cortical networks learn by slowly integrating information across previous experiences in a manner that leads to distributed representations of the statistical structure of environmental input. Such representations are well suited for categorization tasks that require generalization to new exemplars. The hippocampus, on the other hand, is able to quickly learn about the specifics of individual events in a manner that fosters separate, distinctive representations. These hippocampal representations are thought to underlie conscious recollection of prior episodes. The categorical sensitivity of the $\mathrm{N} 1$ is consistent with the operation of the hypothesized cortical networks, whereas the exemplarspecific discrimination of the parietal old/new effect is consistent with the hypothesized characteristics of the hippocampus. The FN400, being sensitive to both in/out and old/new differences, seems to fall somewhere in between. Much like mathematical models of recognition and categorization (e.g., Estes, 1994; Hintzman, 1986, 1988; Medin $\&$ Schaffer, 1978; Nosofsky, 1991), such cortical memory networks are capable of discriminating old from new items in recognition memory tasks (Norman \& O'Reilly, 2001). The N1 and the FN400 sources may reflect the activity of formally similar neuronal networks, but the greater sensitivity of the FN400 to old/new effects may be related to differences in the type of information processed by each (e.g., purely perceptual N1 vs. the FN400, which 
is additionally sensitive to semantics, as was discussed earlier).

Overall, aspects of our results are consistent with both the mathematical modeling (i.e., single-system) and the neuropsychological(i.e., multiple-systems) views reviewed in the introduction. The sensitivity of the FN400 (300$500 \mathrm{msec}$ ) to both categorical and recognition discriminations is consistent with a single, familiarity-based process capable of contributing to both tasks. However, the N1 and the parietal ERP effects seem more suited to categorization and recognition, respectively. The N1 (156-200 msec) was clearly affected by in/out differences more than by old/new differences and so may reflect a process (or system) that contributes to categorization, but not to recognition. Parietal ERP effects (300-500 msec) were less clear but appeared to be more sensitive to old/new than to in/out differences. Given other evidence linking the parietal old/new effect to conscious recollection processing involving the hippocampus, this may reflect the activity of a process that is more likely to underlie recognition memory than categorization. The present results suggest that the brain was sensitive to in/out categorical differences prior to old/new recognition differences, so theories addressing the relationship between categorization and recognition (of either the single- or multiple-system varieties) should account for these temporal dynamics.

\section{REFERENCES}

Alain, C., Achim, A. \& Woods, D. L. (1999). Separate memory-related processing for auditory frequency and patterns. Psychophysiology, 36, 737-744.

Allan, K., Wilding, E. L., \& Rugg, M. D. (1998). Electrophysiological evidence for dissociable processes contributing to recollection. Acta Psychologica, 98, 231-252.

Bentin, S., Allison, T., Puce, A., Perez, E., \& McCarthy, G. (1996). Electrophysiological studies of face perception in humans. Journal of Cognitive Neuroscience, $8,551-565$.

Bentin, S., \& Deouell, L. Y. (2000). Structural encoding and identification in face processing: ERP evidence for separate mechanisms. Cognitive Neuropsychology, 17, 35-54.

Bertrand, O., Perin, F., \& Pernier, J. (1985). A theoretical justification of the average reference in topographic evoked potential studies. Electroencephalography \& Clinical Neuroscience, 62, 462-464.

Besson, M., Kutas, M., \& Van Petten, C. (1992). An event-related potentials (ERP) analysis of semantic congruity and repetition effect in sentences. Journal of Cognitive Neuroscience, 4, 132-149.

Bötzel, K., Schulze, S., \& Stodieck, R. G. (1995). Scalp topography and analysis of intracranial sources of face-evoked potentials. Experimental Brain Research, 104, 135-143.

Brainerd, C. J., Reyna, V. F., \& KneER, R. (1995). False-recognition reversal: When similarity is distinctive. Journal of Memory \& Language, 34, 157-185.

Clark, S. E., \& Gronlund, S. D. (1996). Global matching models of recognition memory: How the models match the data. Psychonomic Bulletin \& Review, 3, 37-60.

Curran, T. (1999). The electrophysiology of incidental and intentional retrieval: ERP old/new effects in lexical decision and recognition memory. Neuropsychologia, 37, 771-785.

Curran, T. (2000). Brain potentials of recollection and familiarity. Memory \& Cognition, 28, 923-938.

Curran, T., Schacter, D. L., Johnson, M. K., \& Spinks, R. (2001). Brain potentials reflect behavioral differences in true and false recognition. Journal of Cognitive Neuroscience, 13, 201-216.
Curran, T., Tucker, D. M., Kutas, M., \& Posner, M. I. (1993). Topography of the N400: Brain electrical activity reflecting semantic expectation. Electroencephalography \& Clinical Neurophysiology, 88, 188-209.

DiEN, J. (1998). Issues in the application of the average reference: Review, critiques, and recommendations. Behavior Research Methods, Instruments, \& Computers, 30, 34-43.

Düzel, E., Vargha-Khadem, F., Heinze, H.-J., \& Mishkin, M. (2001). Brain activity evidence for recognition without recollection after early hippocampal damage. Proceedings of the National Academy of Sciences, 98, 8101-8106.

Düzel, E., Yonelinas, A. P., Mangun, G. R., Heinze, H.-J., \& TulVING, E. (1997). Event-related potential correlates of two states of conscious awareness in memory. Proceedings of the National Academy of Sciences, 94, 5973-5978.

Eimer, M. (1998). Mechanisms of visuospatial attention: Evidence from event-related brain potentials. Visual Cognition, 5, 257-286.

Eimer, M. (2000a). Attentional modulations of event-related brain potentials sensitive to faces. Cognitive Neuropsychology, 17, 103-116.

EIMER, M. (2000b). Event-related brain potentials distinguish processing stages involved in face perception and recognition. Clinical Neurophysiology, 111, 694-705.

Estes, W. K. (1994). Classification and cognition. New York: Oxford University Press.

Friedman, D., \& Johnson, R., JR. (2000). Event-related potential(ERP) studies of memory encoding and retrieval: A selective review. $\mathrm{Mi}$ croscopy Research \& Technique, 51, 6-28.

George, N., Evans, J., Fiori, N., Davidoff, J., \& Renault, B. (1996). Brain events related to normal and moderately scrambled faces. Cognitive Brain Research, 4, 65-76.

Gillund, G., \& Shiffrin, R. M. (1984). A retrieval model for both recognition and recall. Psychological Review, 91, 1-67.

Guillem, F., Bicu, M., \& Debruille, J. B. (2001). Dissociating memory processes involved in direct and indirect tests with ERPs to unfamiliar faces. Cognitive Brain Research, 11, 113-125.

Heckers, S., Curran, T., Goff, D., Rauch, S. L., Fischman, A. J., Alpert, N. M., \& Schacter, D. L. (2000). Abnormalities in the thalamus and prefrontal cortex during episodic object recognition in schizophrenia. Biological Psychiatry, 48, 651-657.

Hintzman, D. L. (1986). "Schema abstraction" in a multiple-trace memory model. Psychological Review, 93, 411-428.

Hintzman, D. L. (1988). Judgments of frequency and recognition memory in a multiple-trace memory model. Psychological Review, 95, 528-551.

Hintzman, D. L., \& CurRan, T. (1994). Retrieval dynamics of recognition and frequency judgments: Evidence for separate processes of familiarity and recall. Journal of Memory \& Language, 33, 1-18.

Humphreys, M. S., Bain, J. D., \& Pike, R. (1989). Different ways to cue a coherent memory system: A theory for episodic, semantic, and procedural tasks. Psychological Review, 96, 208-233.

JACOBY, L. L. (1991). A process dissociation framework: Separating automatic from intentional uses of memory. Journal of Memory \& Language, 30, 513-541.

JASPER, H. A. (1958). The ten-twenty system of the international federation. Electroencepholography \& Clinical Neurophysiology, 10, 371 375.

KIEFER, M. (2001). Perceptual and semantic sources of category-specific effects: Event-related potentials during picture and word categorization. Memory \& Cognition, 29, 100-116.

Kinder, A., \& Shanks, D. R. (2001). Amnesia and the declarative/ nondeclarative distinction: A recurrent network model of classification, recognition, and repetition priming. Journal of Cognitive Neuroscience, 13, 648-669.

Knowlton, B. J. (1999). What can neuropsychology tell us about category learning? Trends in Cognitive Sciences, 3, 123-124.

Knowlton, B. J., Gluck, M. A., \& Seuire, L. R. (1994). Probabilistic classification learning in amnesia. Learning \& Memory, 1, 106-120.

Knowlton, B. J., Mangels, J. A., \& SQuire, L. R. (1996). A neostriatal habit learning system in humans. Science, 273, 1399-1402.

Knowlton, B. J., Ramus, S. J., \& SQuire, L. R. (1992). Intact artificial 
grammar learning in amnesia: Dissociation of classification learning and explicit memory for specific instances. Psychological Science, $\mathbf{3}$, 172-179.

Knowlton, B. J., \& Squire, L. R. (1993). The learning of categories: Parallel brain systems for item memory and category knowledge. Science, 262, 1747-1749.

Knowlton, B. J., \& SQuire, L. R. (1996). Artificial grammar learning depends on implicit acquisition of both abstract and exemplar-specific information. Journal of Experimental Psychology: Learning, Memory, \& Cognition, 22, 169-181.

Kutas, M., \& IRAgUI, V. (1998). The N400 in a semantic categorization task across 6 decades. Electroencephalography \& Clinical Neurophysiology, 108, 456-471.

Kutas, M., \& Van Petten, C. (1994). Psycholinguistics electrified: Event-related brain potential investigations. In M. Gernsbacher (Ed.), Handbook of psycholinguistics (pp. 83-143). New York: Academic Press.

LAMBERTS, K. (2000). Information-accumulation theory of speeded categorization. Psychological Review, 107, 227-260.

Lehman, D., \& Skrandies, W. (1985). Spatial analysis of evoked potentials in man: A review. Progress in Neurobiology, 23, 227-250.

MANDLER, G. (1980). Recognizing: The judgment of previous occurrence. Psychological Review, 87, 252-271.

McCandliss, B. D., Curran, T., \& Posner, M. I. (1993). Repetition effects in processing visual words: A high density ERP study of lateralized stimuli. Society for Neuroscience Abstracts, 19, 1807.

McCandliss, B. D., Curran, T., \& Posner, M. I. (1994, November). Exploring the time course of word recognition for identical and cross-case repetitions. Poster presented at the 35th Annual Meeting of the Psychonomic Society, St. Louis.

McCARThy, G., \& Wood, C. C. (1985). Scalp distributions of event-related potentials: An ambiguity associated with analysis of variance models. Electroencepholography \& Clinical Neurophysiology, 62, 203-208.

McClelland, J. L., McNaughton, B. L., \& O’Reilly, R. C. (1995). Why there are complementary learning systems in the hippocampus and neocortex: Insights from the successes and failures of connectionist models of learning and memory. Psychological Review, 102, 419-457.

Mecklinger, A. (2000). Interfacing mind and brain: A neurocognitive model of recognition memory. Psychophysiology, 37, 565-582.

Medin, D. L., \& Schaffer, M. M. (1978). Context theory of classification learning. Psychological Review, 85, 207-238.

Murdock, B. B. (1982). A theory of the storage and retrieval of item and associative information. Psychological Review, 89, 609-626.

Nessler, D., Mecklinger, A., \& Penney, T. B. (2001). Event related brain potentials and illusory memories: The effects of differential encoding. Cognitive Brain Research, 10, 283-301.

Norman, K. A., \& O'Reilly, R. C. (2001). Modeling hippocampaland neocortical contributions to recognition memory: A complementary learning systems approach (ICS Tech. Rep. 01-02). Boulder: University of Colorado, Institute of Cognitive Science.

NosOFSKY, R. M. (1988). Exemplar-based accounts of the relations between classification, recognition, and typicality. Journal of Experimental Psychology: Learning, Memory, \& Cognition, 14, 700-708.

NosOFSKY, R. M. (1991). Tests of an exemplar model for relating perceptual classification and recognition memory. Journal of Experimental Psychology: Human Perception \& Performance, 17, 3-27.

Nosofsky, R. M., \& Alfonso-Reese, L. A. (1999). Effects of similarity and practice on speeded classification response times and accuracies: Further tests of an exemplar-retrieval model. Memory \& Cognition, 27, 78-93.

NosofSKY, R. M., \& ZAKI, S. (1998). Dissociations between categorization and recognition in amnesic and normal individuals: An exemplarbased interpretation. Psychological Science, 9, 247-255.

NosOFSKY, R. M., \& ZAKI, S. (1999). Math modeling, neuropsychology, and category learning. Trends in Cognitive Sciences, 3, 125-126.

Olichney, J. M., Van Petten, C., Paller, K. A., Salmon, D. P., IRAGUI, V. J., \& KUTAS, M. (2000). Word repetition in amnesia: Electrophysiological measures of impaired and spared memory. Brain, 123, 1948-1963.

O'ReIlly, R. C., \& Rudy, J. W. (2001). Conjunctive representations in learning and memory: Principles of cortical and hippocampal function. Psychological Review, 108, 311-345.

Paller, K. A., \& Kutas, M. (1992). Brain potentials during memory retrieval provide neurophysiological support of the distinction between conscious recollection and priming. Journal of Cognitive Neuroscience, 4, 375-391.

Paller, K. A., Kutas, M., \& McIsaac, H. K. (1995). Monitoring conscious recollection via the electrical activity of the brain. Psychological Science, 6, 107-111.

Palmeri, T., \& Flanery, M. (1999). Learning about categories in the absence of training: Profound amnesia and the relationship between perceptual categorization and recognition memory. Psychological Science, 10, 526-530.

Picton, T. W., Bentin, S., Berg, P., Donchin, E., Hillyard, S. A. Johnson, R., Jr., Miller, G. A., Ritter, W., Ruchin, D. S., RugG, M. D., \& TAY LOR, M. J. (2000). Guidelines for using human eventrelated potentials to study cognition: Recording standards and publication criteria. Psychophysiology, 37, 127-152.

Picton, T. W., Lins, O. G., \& Scherg, M. (1995). The recording and analysis of event-related potentials. In F. Boller \& J. Grafman (Eds.), Handbook of neuropsychology (Vol. 10, pp. 3-73). Amsterdam: Elsevier.

Posner, M. I., \& Keele, S. W. (1968). On the genesis of abstract ideas. Journal of Experimental Psychology, 77, 353-363.

Posner, M. I., \& McCANDLISS, B. D. (1999). Brain circuitry during reading. In R. Klein \& P. McMullen (Eds.), Converging methods for understanding reading and dyslexia (pp. 305-337). Cambridge, MA: MIT Press.

Reber, P. J., Stark, C. E., \& Squire, L. R. (1998a). Contrasting cortical activity associated with category memory and recognition memory. Learning \& Memory, 5, 420-428.

Reber, P. J., Stark, C. E., \& SQuire, L. R. (1998b). Cortical areas supporting category learning identified using functional MRI. Proceedings of the National Academy of Sciences, 95, 747-750.

Reed, J. M., Squire, L. R., Patalano, A. L., Smith, E. E., \& Jonides, J. (1999). Learning about categories that are defined by object-like stimuli despite impaired declarative memory. Behavioral Neuroscience, 113, 411-419.

Rossion, B., Campanella, S., Gomez, C. M., Delinte, A., Debatisse, D., Liard, L., Dubois, S., Bruyer, R., Crommelinck, M., \& GuÉRIT, J.-M. (1999). Task modulation of brain activity related to familiar and unfamiliar face processing: An ERP study. Clinical Neurophysiology, 110, 449-462.

Rossion, B., Delvenne, J.-F., Debatisse, D., Goffaux, V., Bruyer, R. Crommelinck, M., \& GuÉrit, J.-M. (1999). Spatio-temporal localization of the face inversion effect: An event-related potentials study. Biological Psychology, 50, 173-189.

RugG, M. D. (1995). ERP studies of memory. In M. D. Rugg \& M. G. H. Coles (Eds.), Electrophysiology of mind (pp. 132-170). New York: Oxford University Press.

RugG, M. D., CoX, C. J. C., Doy le, M. C., \& Wells, T. (1995). Eventrelated potentials and the recollection of low and high frequency words. Neuropsychologia, 33, 471-484.

Rugg, M. D., Mark, R. E., Walla, P., Schloerscheidt, A. M., Birch, C. S., \& Allan, K. (1998). Dissociation of the neural correlates of implicit and explicit memory. Nature, 392, 595-598.

RUGG, M. D., \& NAGY, M. E. (1989). Event-related potentials and recognition memory for words. Electroencephalography \& Clinical Neurophysiology, 72, 395-406.

RugG, M. D., Schloerscheidt, A. M., \& Mark, R. E. (1998). An electrophysiological comparison of two indices of recollection. Journal of Memory \& Language, 39, 47-69.

Schacter, D. L., Curran, T., Reiman, E. M., Chen, K., Bandy, D. J., \& Frost, J. T. (1999). Medial temporal lobe activation during episodic encoding and retrieval: A PET study. Hippocampus, 9, 575-581.

Schacter, D. L., Reiman, E., Uecker, A., Polster, M. R, Yun, L. S., \& Cooper, L. A. (1995). Brain regions associated with retrieval of structurally coherent visual information. Nature, 376, 587-590.

SCHACTER, D. L., \& Tulving, E. (1994). What are the memory systems of 1994? In D. L. Schacter \& E. Tulving (Eds.), Memory systems 1994 (pp. 1-38). Cambridge, MA: MIT Press.

Schacter, D. L., Uecker, A., Yun, L. S., Bandy, D., Chen, K., 
Cooper, L. A., \& Curran, T. (1997). Effects of size and orientation change on hippocampal activation during episodic recognition: A PET study. NeuroReport, 8, 3993-3998.

Sherry, D. F., \& Schacter, D. L. (1987). The evolution of multiple memory systems. Psychological Review, 94, 439-454.

Shiffrin, R. M., \& Steyvers, M. (1997). A model for recognition memory: REM-retrieving effectively from memory. Psychonomic Bulletin \& Review, 4, 145-166.

Smith, M. E. (1993). Neurophysiological manifestations of recollective experience during recognition memory judgments. Journal of Cognitive Neuroscience, 5, 1-13.

Smith, M. E., \& Halgren, E. (1989). Dissociation of recognition memory components following temporal lobe lesions. Journal of Experimental Psychology: Learning, Memory, \& Cognition, 15, 50-60.

Spencer, K. M., Vila Abad, E., \& Donchin, E. (2000). On the search for the neurophysiological manifestation of recollective experience. Psychophysiology, 37, 494-506.

SQuire, L. R., \& KNOWLTON, B. J. (1995). Learning about categories in the absence of memory. Proceedings of the National Academy of Sciences, 92, 12470-12474.

Srinivasan, R., Nunez, P. L., Silberstein, R. B., Tucker, D. M., \& CADUSCH, P. J. (1996). Spatial sampling and filtering of EEG with splineLaplacians to estimate cortical potentials. Brain Topography, 8, 355-366.

TANAKa, J. W., \& Curran, T. (2001). A neural basis for expert object recognition. Psychological Science, 12, 43-47.

Tanaka, J. [W.], LuU, P., Weisbrod, M., \& Kiefer, M. (1999). Tracking the time course of object categorization using event-related potentials. NeuroReport, 10, 829-835.

Taylor, M. J., McCarthy, G., Saliba, E., \& Degiovanni, E. (1999). ERP evidence of developmental changes in processing of faces. Clinical Neurophysiology, 110, 910-915.

Trott, C. T., Friedman, D., Ritter, W., \& Fabiani, M. (1997). Item and source memory: Differential age effects revealed by event-related potentials. NeuroReport, 8, 3373-3378.

TucKer, D. M. (1993). Spatial sampling of head electrical fields: The geodesic sensor net. Electroencephalography \& Clinical Neurophysiology, 87, 154-163.

Tucker, D. M., Lotti, M., Potts, G. F., Russell, G. S., \& Posner, M. I. (1994). Spatiotemporal analysis of brain electrical fields. Human Brain Mapping, 1, 134-152.
Van Petten, C., Kutas, M., Kluender, R., Mitchiner, M., \& McIsaAc, H. (1991). Fractionating the word repetition effect with eventrelated potentials. Journal of Cognitive Neuroscience, 3, 131-150.

Vogel, E. K., \& LucK, S. J. (2000). The visual N1 component as an index of a discrimination process. Psychophysiology, 37, 190-203.

Wilding, E. L., Doy le, M. C., \& Rugg, M. D. (1995). Recognition memory with and without retrieval of context: An event-related potential study. Neuropsychologia, 33, 743-767.

WiLDING, E. L., \& RUGG, M. D. (1996). An event-related potential study of recognition memory with and without retrieval of source. Brain, 119, 889-905.

Wilding, E. L., \& RUGG, M. D. (1997a). Event-related potential and the recognition memory exclusion task. Neuropsychologia, 35, 119-128.

WiLDING, E. L., \& RUGG, M. D. (1997b). An event-related potential study of recognition memory for words spoken aloud or heard. Neuropsychologia, 35, 1185-1195.

\section{NOTES}

1. Using the average reference may help explain the consistent frontal focus of the FN400 in our laboratory, but similar frontal effects have been observed relative to a mastoid reference (Friedman \& Johnson, 2000; Guillem, Bicu, \& Debruille, 2001; Mecklinger, 2000; Rugg, Mark, et al., 1998).

2. Thirteen subjects were excluded for the following reasons. Six subjects failed to attend the second session. Five subjects did not have sufficient trials in all conditions because of low accuracy $(n=3)$ or excessive blinking $(n=2)$. The data from 2 subjects were not usable because of equipment problems.

3 . The primary analyses concentrated on only the negative PI aspects of the N1, but the co-occurrence of AS positive potentials is common. The face-enhanced N170 recorded near the mastoids is often accompanied by a vertex positive potential (VPP; Bentin et al., 1996; Bötzel et al., 1995; Eimer, 1998, 2000a, 2000b; George et al., 1996; Rossion, Campanella, et al., 1999). The VPP and N1 may reflect activity within a common generator process (George et al., 1996), but others have argued for different sources (Bötzel et al., 1995).

4. Four subjects were excluded. Two subjects had excessively noisy EEG. A computer crash prematurely terminated the experiment for 1 subject. One subject blinked excessively. 


\section{APPENDIX}

Mean Masatoid-Referenced ERPs From Channels Nearest to Several Locations of the International 10-20 System (ERPs Have Been Averaged Across Tasks)
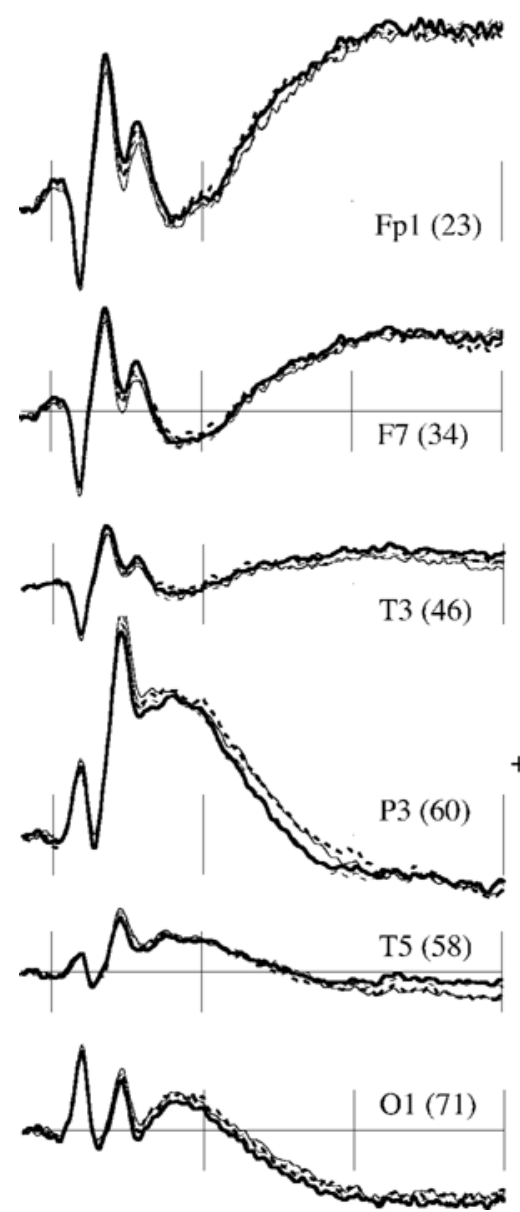
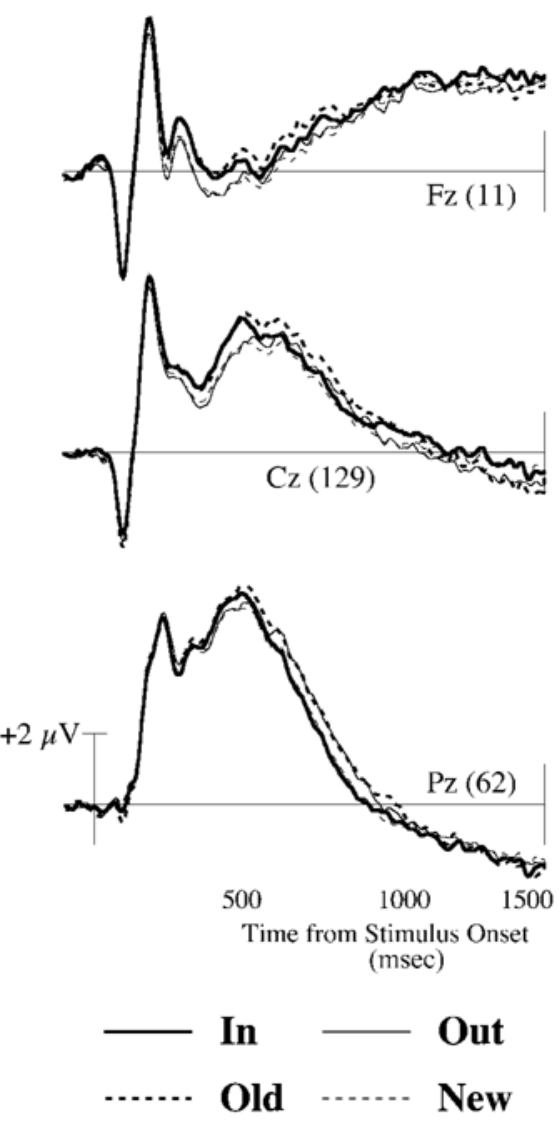
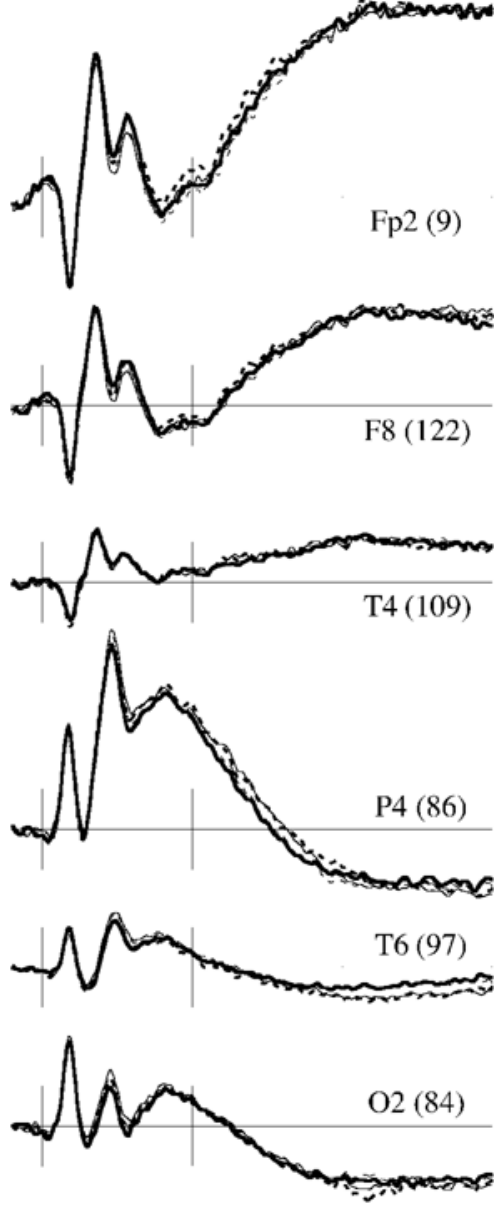

(Manuscript received July 13, 2001;

revision accepted for publication December 20, 2001.) 